\title{
Impact of Dense and Frequent Surface Observations on 1-Minute-Update Severe Rainstorm Prediction: A Simulation Study
}

\author{
Yasumitsu MAEJIMA \\ RIKEN Center for Computational Science (R-CCS), Kobe, Japan \\ Takemasa MIYOSHI \\ RIKEN Center for Computational Science (R-CCS), Kobe, Japan \\ RIKEN interdisciplinary Theoretical and Mathematical Sciences Program, Kobe, Japan \\ RIKEN Cluster for Pioneering Research, Kobe, Japan \\ University of Maryland, Maryland, USA. \\ Japan Agency for Marine-Earth Science and Technology, Yokohama, Japan
}

\section{Masaru KUNII}

Numerical Prediction Division, Japan Meteorological Agency, Tokyo, Japan

Meteorological Research Institute, Japan Meteorological Agency, Tsukuba, Japan

\section{Hiromu SEKO}

Meteorological Research Institute, Japan Meteorological Agency, Tsukuba, Japan Japan Agency for Marine-Earth Science and Technology, Yokohama, Japan

and

Kae SATO

Meisei Electric Co., Ltd, Isesaki, Japan

(Manuscript received 6 March 2018, in final form 5 November 2018)

\begin{abstract}
This study aims to investigate the potential impact of surface observations with a high spatial and temporal density on a local heavy rainstorm prediction. A series of Observing System Simulation Experiments (OSSEs) are performed using the Local Ensemble Transform Kalman Filter with the Japan Meteorological Agency non-hydrostatic model at 1-km resolution and with 1-minute update cycles. For the nature run of the OSSEs, a 100-m resolution simulation is performed for the heavy rainstorm case that caused five fatalities in Kobe, Japan on July 28, 2008. Synthetic radar observation data, both reflectivity and Doppler velocity, are generated at 1-km resolution every minute from the $100-\mathrm{m}$ resolution nature run within a $60-\mathrm{km}$ range, simulating the phased array weather radar (PAWR) at Osaka
\end{abstract}

Corresponding author: Yasumitsu Maejima, RIKEN Center for Computational Science (R-CCS), 7-1-26, Minatojimaminami-machi, Chuo-ku, Kobe, Hyogo 650-0047, Japan

E-mail: yasumitsu.maejima@riken.jp

J-stage Advance Published Date: 16 November 2018

CThe Author(s) 2019. This is an open access article published by the Meteorological Society of Japan under a Creative Commons Attribution 4.0 International (CC BY 4.0) license (https://creativecommons.org/licenses/by/4.0). 
University. The control experiment assimilates only the radar data, and two sensitivity experiments are performed to investigate the impact of additional surface observations obtained every minute at 8 and 167 stations in Kobe. The results show that the dense and frequent surface observations have a significant positive impact on the analyses and forecasts of the local heavy rainstorm, although the number of assimilated observations is three orders of magnitude less than the PAWR data. Equivalent potential temperature and convergence at the low levels are improved, contributing to intensified convective cells and local heavy rainfalls.

Keywords surface data assimilation; local ensemble transform Kalman filter; rainfall prediction

Citation Maejima, Y., T. Miyoshi, M. Kunii, H. Seko, and K. Sato, 2019: Impact of dense and frequent surface observations on 1-minute-update severe rainstorm prediction: A simulation study. J. Meteor. Soc. Japan, 97, 253-273, doi:10.2151/jmsj.2019-014.

\section{Introduction}

A sudden local rainstorm in the summer season is usually associated with a cumulonimbus with active convection. To predict the hazardous severe weather caused by such a rainstorm, numerical weather prediction (NWP) and data assimilation (DA) play an essential role (e.g., Brooks and Doswell 2002; Pielke and Carbone 2002; Simmons and Sutter 2005; Theis et al. 2005). Stensrud et al. $(2009,2013)$ reported the National Oceanic and Atmospheric Administration (NOAA)'s "Warn-on-Forecast" effort on NWP and DA experiments using the Ensemble Kalman Filter (EnKF, Evensen 1994) for severe convective weather events. Yussouf and Stensrud (2010) performed Observing System Simulation Experiments (OSSEs) using an EnKF system to assess the impact of assimilating phased array radar data every minute at $1-\mathrm{km}$ resolution and showed that it has a potential to improve 50-minute forecasts of severe convective weather. Yussouf et al. (2013) performed a real-case DA experiment at $2-\mathrm{km}$ resolution with every 3-minute Doppler radar data and showed promising results. Also, Schwartz et al. (2015) have been working on the Short Term Explicit Prediction Program (STEP), and developed an EnKF system at $15-\mathrm{km}$ resolution and a real-time forecast system at $3-\mathrm{km}$ resolution, based on the EnKF. Their results showed improvements in meso-scale precipitation forecasts. More recently, Miyoshi et al. (2016a, b) reported Japan's “Big Data Assimilation (BDA)" project that proposed orders of magnitude more rapidly updated and higher-resolution NWP by taking advantage of the next-generation remote sensing and supercomputing technologies, such as the Phased Array Weather Radar (PAWR, Wu et al. 2013; Yoshikawa et al. 2013; Ushio et al. 2015), which has resolutions of $100 \mathrm{~m}$ in radial direction, $1^{\circ}$ in azimuth angle and 200 levels in elevation angle, and a 100-member EnKF with 100-m resolution conducted by the 10-petaflops $\mathrm{K}$ computer. They developed a prototype BDA system with super-rapid 30-second update cycles and showed encouraging results for real-case severe convective weather.

It is generally well known that the surface atmospheric conditions are important for the lifecycle evolution of a cumulonimbus (e.g., Troen and Mahrt 1986; Ogura and Yoshizaki 1988; Chen and Avissar 1994; Elfatih and Jeremy 1996; Ducrocq et al. 2002). For example, convergence of warm and moist air mass near the surface is favorable for convective initiation. Therefore, it would be important to improve the near-surface atmospheric conditions in NWP, and a number of studies have explored to assimilate surface observation data for improving severe convective weather prediction. For example, Hacker and Snyder (2005) proposed an approach to improve the planetary boundary layer using a single-column model. Fujita et al. (2007) performed a real-case EnKF experiment in the summer season and demonstrated the impact of surface data on improving the analysis of mesoscale features favorable to active convection. Järvinen et al. (1999) implemented surface DA with the European Centre for Medium-Range Weather Forecasts (ECMWF) operational four-dimensional variational (4D-VAR) DA system and improved forecasts up to 96 hours. Zhang et al. (2006) and Meng and Zhang (2007, 2008) discussed the reproducibility of meso-scale cyclones by EnKF experiments with surface data. Ha and Snyder (2014) performed DA and forecast experiments using surface data from the aviation routine weather report (METAR) stations and showed that the surface DA leads to an improvement of rainfall amount due to the improved analysis in the planetary boundary layer. Gustafsson et al. (2018) reviewed the 


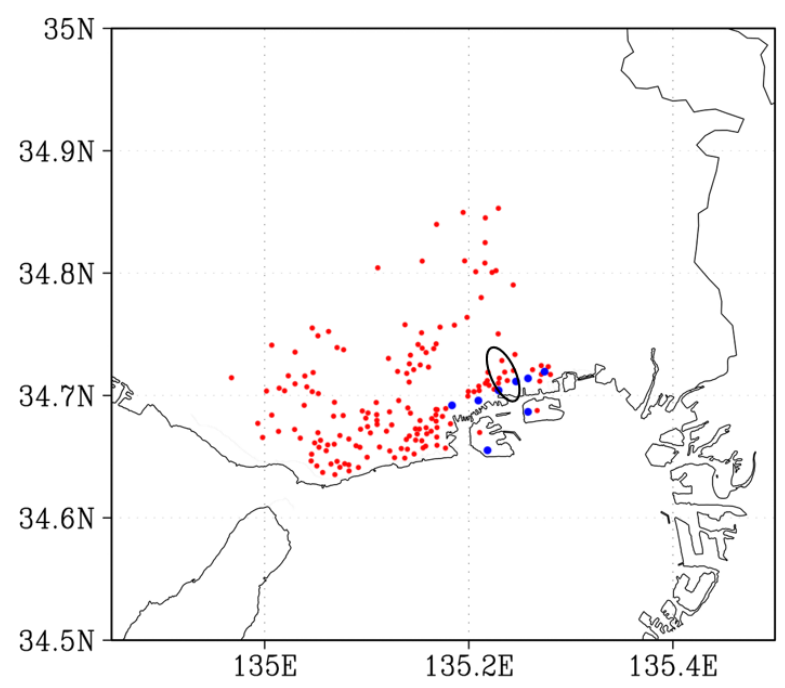

Fig. 1. Locations of the surface weather stations. Red and blue dots indicate the positions of all elementary schools in Kobe city and RIKEN Center for Computational Science (167 stations). Blue dots indicate the observation sites (8 stations). Black ellipse indicates the location of River Toga.

operational DA methods for convective scale NWP and discussed the surface DA technique at operational centers.

Following the success of the previous studies, the present study aims to investigate the potential impacts of assimilating dense and frequent surface observations on a sudden local rainstorm prediction in the framework of BDA by Miyoshi et al. (2016a, b). Previous studies focused on rainstorms with scales at several tens of kilometers or larger. Here we explore one kilometer order scale severe weather with a high observing density of several kilometers and every minute. Meisei Electric developed an affordable auto- mated weather station named "POTEKA II", which can observe wind speed and direction, temperature, pressure, relative humidity, sunshine, and rainfall amount every 30 seconds, although with relatively larger errors compared with high-cost operational automated weather stations. The idea is to deploy a large number of the low-cost instruments, and this study explores how we could use these dense and frequent surface observation data in convective-scale NWP. We installed the "POTEKA II" stations at seven Kobe city elementary schools and RIKEN Center for Computational Science (R-CCS) (Fig. 1, blue dots) and have been getting the data in real time since summer 2013. This study performs a series of OSSEs for a case of a disastrous heavy rainstorm that caused five fatalities in Kobe, Japan on July 28, 2008. The "POTEKA II" stations were not deployed yet in 2008, and we do not use real observation data in this study. Instead, we simulate surface station data at all Kobe city elementary schools (167 locations, Fig. 1) to investigate the potential impact of dense and frequent surface station data on heavy rainfall prediction.

This paper is organized as follows. Section 2 describes the experimental settings, and Section 3 presents the results. Finally, Section 4 provides the conclusion.

\section{Experimental settings}

\subsection{Nature run at 100-m resolution}

This study used the Japan Meteorological Agency non-hydrostatic model (JMA-NHM; Saito et al. 2006, 2007), which was used as the operational mesoscale NWP model in JMA from September 2004 to February 2017. Previous studies used the JMA-NHM to investigate heavy rainfall events around Japan (e.g., Kato 2006; Seko et al. 2007, 2011).

Figure 2 shows the hourly JMA radar echo composition data on July 28, 2008, which captured strong
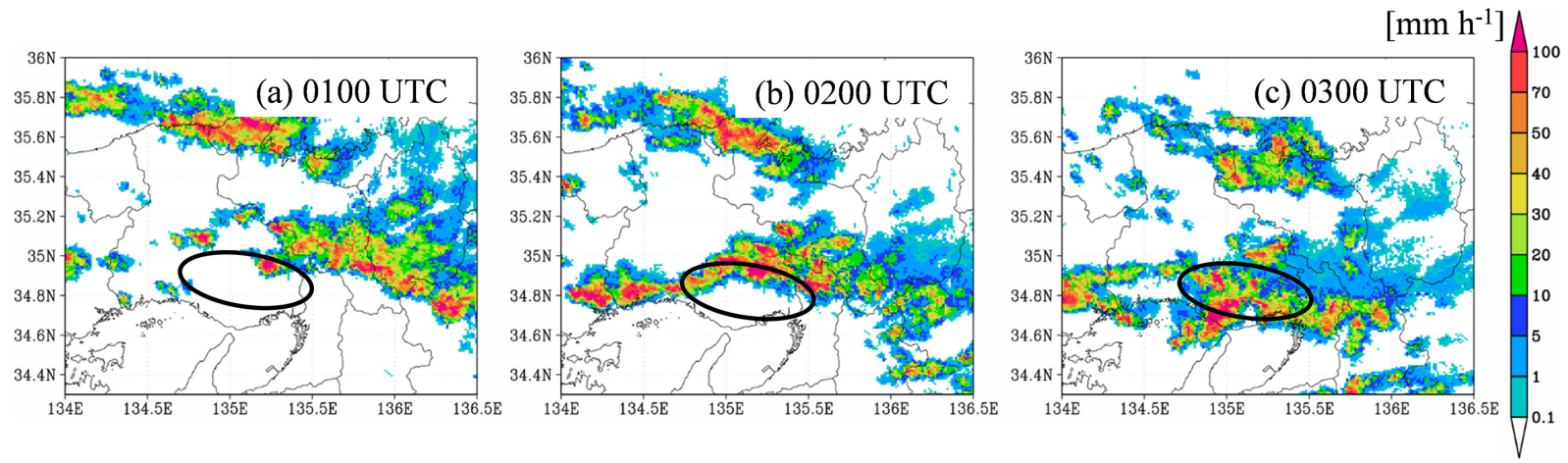

Fig. 2. JMA radar echo composition data at (a) 0100 UTC, (b) 0200 UTC, and (c) 0300 UTC. 
convective cells around the northern part of Kobe city (black ellipses). A well-developed linear rainband was formed by 0100 UTC (Fig. 2a). The intense rainfall region was extended to the west (Fig. 2b) and moved southward with significant rainfall intensity (Fig. 2c). As the rainband approached Kobe, an intense rainfall over $100 \mathrm{~mm} \mathrm{~h}^{-1}$ occurred, and a large amount of water flowed into River Toga, an urban river located in Kobe. Its water level rose by $1.3 \mathrm{~m}$ within only 10 minutes and caused five fatalities, although the river did not overflow.

This event was carefully studied by Kusabiraki et al. (2011). In the northern part of the rainband, we found a significant cold pool and outflow near the surface, whereas from the southern side, warm and moist southwestern winds flowed into the rainband. The intense low-level convergence of the low and high potential temperature air masses maintained and enhanced the rainband. Shoji et al. (2009) mentioned the difficulty of the prediction of the event by the operational JMA-NHM at 5-km resolution.

Seko et al. (2011) simulated this disastrous case in Kobe successfully using the JMA-NHM at $5-\mathrm{km}$ resolution by assimilating precipitable water vapor data from the zenith delay observations of Global Positioning System using the Local Ensemble Transform Kalman Filter (LETKF; Hunt et al. 2007). In the present study, we performed a downscale simulation of the best ensemble member of Seko et al. (2011) and generated the $100-\mathrm{m}$ resolution nature run for OSSEs using the JMA-NHM. To simulate the detailed

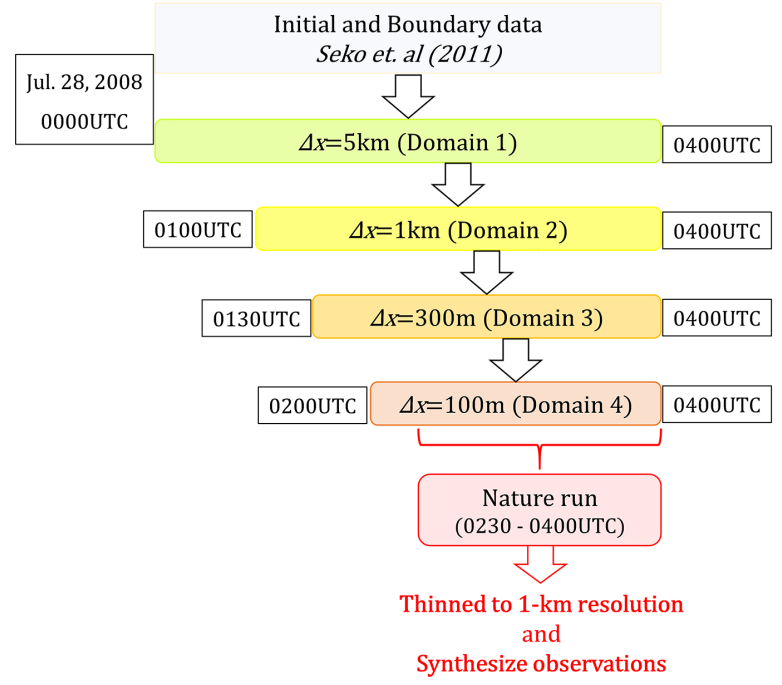

Fig. 3. Workflow of generating the nature run. structure of this heavy rainfall event as shown by Kusabiraki et al. (2011), the nature run was performed at $100-\mathrm{m}$ resolution. Here, we take a typical multipledomain nesting strategy with gradually refining the resolution (Fig. 3). Figure 4 shows the nested model domains from Domains 1 to 4 , and Table 1 summarizes the model settings for each domain, including the initial times on July 28 . The initial and boundary

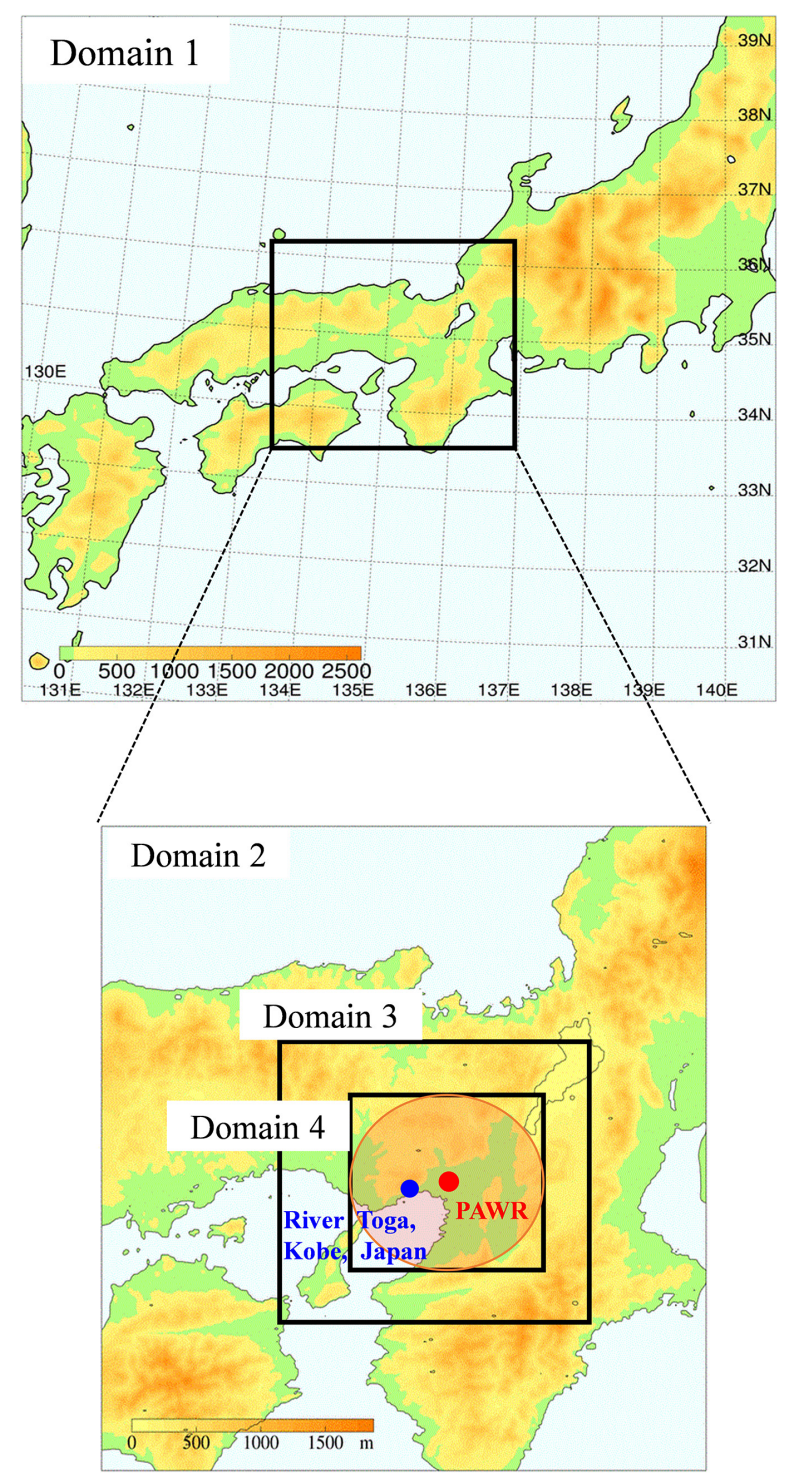

Fig. 4. Nested model domains for the nature run. Red circle indicates the location of PAWR at Osaka University, and blue circle indicates River Toga in Kobe city. Red shaded circle shows the observation range of the PAWR. Color shading shows topography. 
conditions for the outer-most Domain 1 come from the ensemble member of the LETKF experiment by Seko et al. (2011). We chose the ensemble member best representing the actual observed rainband.

The inner-most domain (Domain 4) was used for the nature run at $100-\mathrm{m}$ resolution, simulating the main features of the heavy rainfall event, including the intense linear rainband moving southward (Fig. 5a) and the north-south low-level temperature contrast along the rainband (Fig. 5b). Figure 5a shows the precipitation intensity maximum over $100 \mathrm{~mm} \mathrm{~h}^{-1}$, close to the JMA composite weather radar echoes although the timing is slightly delayed by approximately 20 minutes as in Seko et al. (2011). These features are consistent with the analyzes by Kusa- biraki et al. (2011).

\section{2. $O S S E$}

Figure 6 summarizes the general OSSE workflow. This study performs a series of LETKF experiments at reduced $1-\mathrm{km}$ resolution with 40 ensemble members and assimilates PAWR data and surface observations generated from the nature run at $100-\mathrm{m}$ resolution. Here, we include the model error originated from the different model resolutions. In the OSSEs, we assimilate simulated observations, not real observation data. In fact, neither the PAWR nor the POTEKA II stations were available in 2008. The detailed workflow is described as follows.

Table 1. Model settings for nature run.

\begin{tabular}{lcccc}
\hline & Domain 1 & Domain2 & Domain3 & Domain4 \\
\hline Horizontal resolution & $5 \mathrm{~km}$ & $1 \mathrm{~km}$ & $300 \mathrm{~m}$ & $100 \mathrm{~m}$ \\
\hline Initial time & $0000 \mathrm{UTC}$ & $0100 \mathrm{UTC}$ & 0130 UTC & 0200 UTC \\
\hline Integrate time & 9 hours & 5 hours & 3 hours & 2 hours \\
\hline Grid points & $201 \times 201$ & $301 \times 301$ & $641 \times 641$ & $1201 \times 1201$ \\
\hline Vertical levels & & 50 & & None \\
\hline Cumulus parameterization & Kain-Fritsch (Kain and Fritsch 1990, 1993) & & Deardorff (1973) \\
\hline Cloud micro physics & 6-category single moment but double moments for only cloud ice (Ikawa and Saito 1991) \\
\hline Subgrid turbulence scheme & \multicolumn{2}{c}{$\begin{array}{c}\text { Improved Mellor-Yamada Level-3 } \\
\text { (Nakanishi and Niino 2006, 2009) }\end{array}$} & & \\
\hline
\end{tabular}

(a) Rain faill intensity $\left[\mathrm{mm} \mathrm{h}^{-1}\right]$

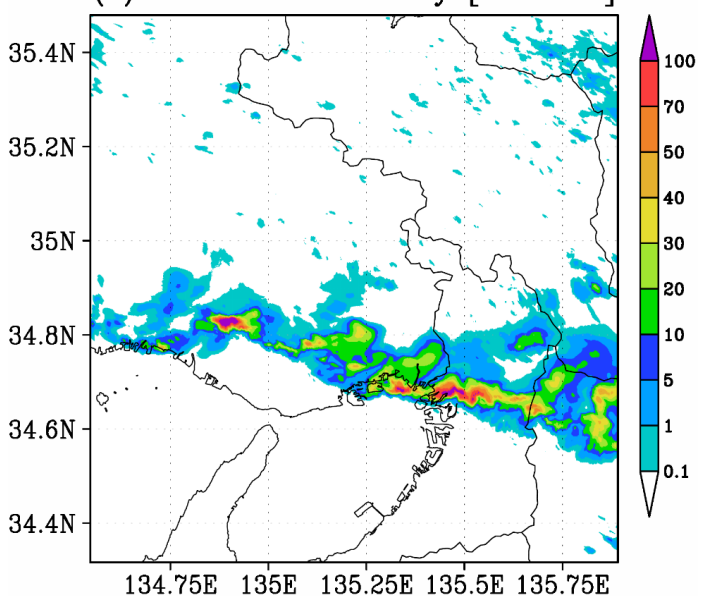

(b) Temperature $\left[{ }^{\circ} \mathrm{C}\right]$

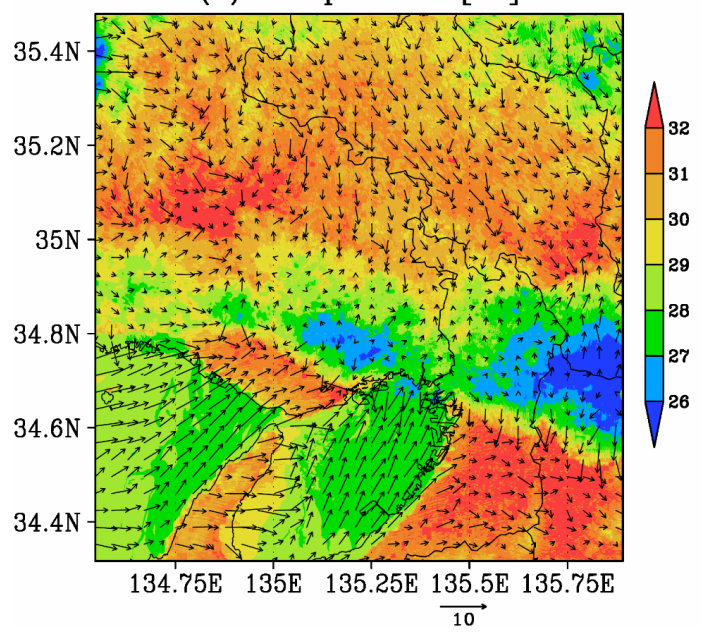

Fig. 5. Nature run (Domain 4) at 0320 UTC July 28, 2008. (a) Rainfall intensity (shades, $\mathrm{mm} \mathrm{h}^{-1}$ ) and (b) mean-sealevel temperature (shades) and near-surface horizontal winds (vectors). 

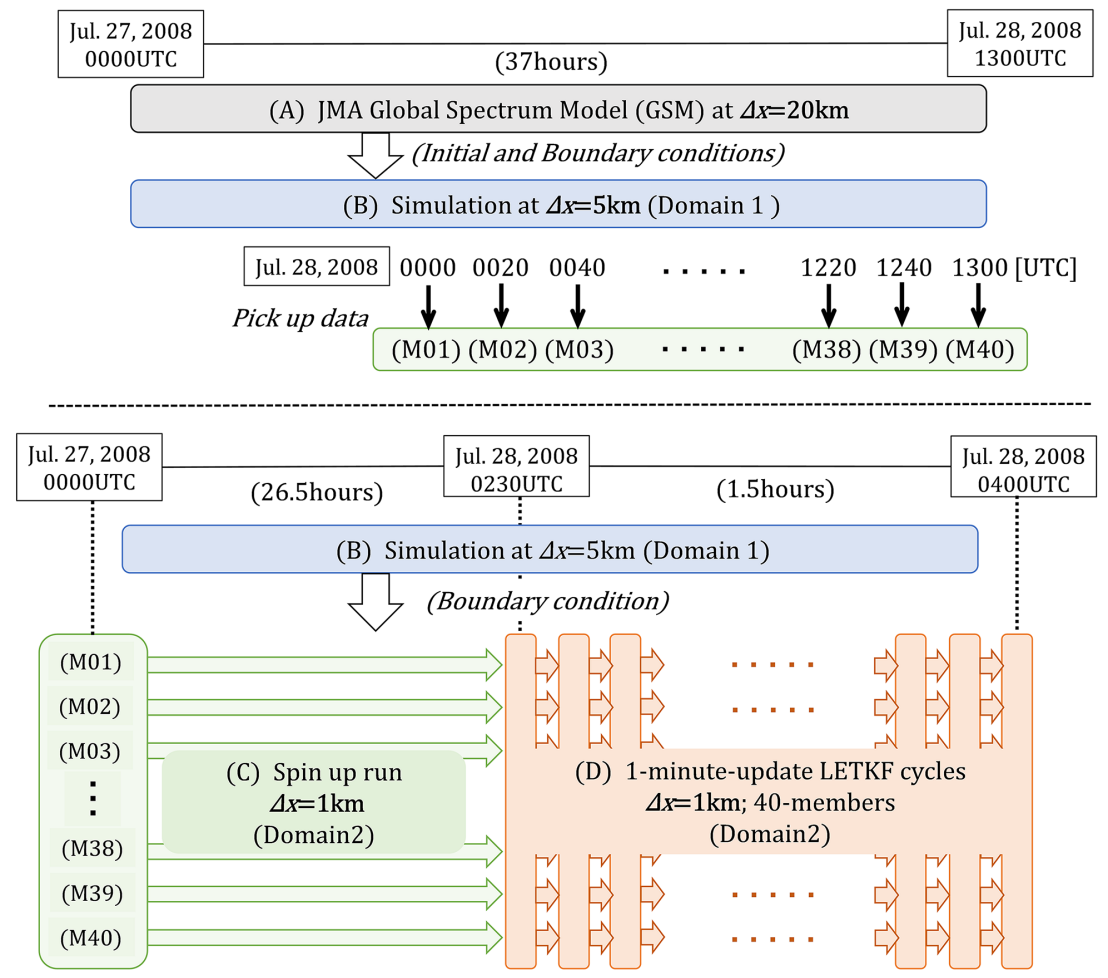

Fig. 6. Overview of the OSSEs. (a) The generation method of the initial states at 0000 UTC July 27, 2008. (b) Workflow of spin-up run and 1-minute update LETKF cycles.

\section{a. Initial ensemble members}

Figure 6 summarizes how the initial ensemble members of the LETKF were generated. First, a $37-$ hour numerical simulation at $5-\mathrm{km}$ resolution for Domain 1 was performed (Fig. 6a, blue bar). Here, the initial and boundary conditions were obtained from the operational JMA Global Spectral Model (JMAGSM) forecasts initialized at 0000 UTC July 27 at $20-\mathrm{km}$ resolution. Forty ensemble members were chosen from the simulation at different times (Fig. $6 \mathrm{a}$, green bar). The first member (M01) was chosen at 0000 UTC July 28 after a 24-hour spin-up, the second member (M02) at 0020 UTC, the third member (M03) at 0040 UTC, and similarly to the 40th member (M40) at 1300 UTC. Although the forecast times are different, these 40 ensemble fields at $5-\mathrm{km}$ resolution were assumed as the initial conditions at 0000 UTC July 27, 2008 (Fig. 6b, leftmost vertical green bar). The 40 ensemble fields of Domain 2 at $1-\mathrm{km}$ resolution were interpolated from the $5-\mathrm{km}$ resolution fields and were integrated for 26.5 hours to generate the initial ensemble members of the LETKF experiments at $1-\mathrm{km}$ resolution at 0230 UTC July 28 (Fig. 6b, green arrows). Here, the lateral boundary conditions were produced from the $5-\mathrm{km}$ simulation (Fig. 6b, blue bar), so that there is no ensemble perturbation at the lateral boundaries. The ensemble initial conditions have relatively large errors, and we investigate the impacts of dense and frequent surface DA on the severe rainfall prediction.

\section{b. DA cycles}

From 0230 UTC July 28, NHM-LETKF (Miyoshi and Aranami 2006; Kunii 2014) with 1-km resolution in Domain 2 was cycled every minute for 1.5 hours (from 0230 UTC to 0400 UTC) with the boundary conditions from the simulation initialized at 0000 UTC July 27 at 5-km resolution (Fig. 6b, red). The localization scale was chosen to be $2000 \mathrm{~m}$ in the horizontal and $1000 \mathrm{~m}$ in the vertical (Table 2), where the localization length corresponds to a standard deviation of the Gaussian function. The cutoff lengths are given by $2 \sqrt{10 / 3} \sigma$, where $\sigma$ is the localization length standard deviations, i.e., $7302 \mathrm{~m}$ in the horizontal and $3651 \mathrm{~m}$ in the vertical (Table 2). Adaptive covariance inflation by Miyoshi (2011) was adopted. 
Table 2. General settings for LETKF.

\begin{tabular}{cc}
\hline NHM Resolution & $\begin{array}{c}1 \mathrm{~km} \text { (horizontal), } \\
50 \text { layers (vertical) }\end{array}$ \\
\hline Assimilation window & 1 minute \\
\hline Ensemble members & 40 \\
\hline Inflation method & $\begin{array}{c}\text { Adaptive covariance inflation } \\
\text { (Miyoshi 2011) }\end{array}$ \\
\hline $\begin{array}{c}\text { Localization length } \\
\text { standard deviation } \\
\text { (Cut off length) }\end{array}$ & $\begin{array}{c}2000 \mathrm{~m} \mathrm{(7302} \mathrm{m)} \mathrm{in} \mathrm{horizontal,} \\
1000 \mathrm{~m}(3651 \mathrm{~m}) \text { in vertical }\end{array}$ \\
\hline
\end{tabular}

\section{c. Synthetic observation data}

To perform a series of $1-\mathrm{km}$ mesh OSSEs and to simulate synthetic observation data, we conducted the $100-\mathrm{m}$ mesh nature run. As described above, neither the PAWR nor the POTEKA II stations were available in 2008, and real observation data do not exist. The synthetic reflectivity and radial wind of PAWR data with the polar coordinate were simulated from the $100-\mathrm{m}$ resolution nature run by applying the observation operator by Maejima et al. (2017). The simulated PAWR data were interpolated to the Cartesian coordinate at $100-\mathrm{m}$ horizontal resolution and were converted to $1-\mathrm{km}$ horizontal resolution by averaging the $10-$ by-10 pixel values of $100-\mathrm{m}$ resolution for each $1-\mathrm{km}$ pixel. The number of independent unbiased white observational noise from a normal distribution was added to each datum; the error standard deviations are assumed to be $10 \%$ for both reflectivity and radial velocity but fixed at $2 \mathrm{dBZ}$ if it becomes less than 2 $\mathrm{dBZ}$ for reflectivity and, similarly, fixed at $3 \mathrm{~m} \mathrm{~s}^{-1}$ for radial velocity (Table 3). Observation error bias is not considered explicitly, although the resolution difference between the nature run $(100 \mathrm{~m})$ and DA experiments $(1 \mathrm{~km})$ might contain biased differences implicitly.

For the surface data, we first identified the locations of all Kobe city elementary schools (Fig. 1, red and blue dots) from the official website of the Kobe city government (http://www.city.kobe.lg.jp/safety/ prevention/evacuation/). The $100-\mathrm{m}$ resolution nature run at the lowest model level (20 m elevation) was interpolated bi-linearly in the horizontal to the locations of the elementary schools. In the vertical, the actual elevations of the surface stations were not considered, and we used simply the lowest model level data. Similar to the PAWR data, independent unbiased white random noise from a normal distribution was added to the interpolated nature run data to simulate the observation noise. Table 3 shows the observed variables and corresponding error standard deviations for the simulated observations. The observation error standard deviations are set to be larger than the instrumental errors by considering additional errors from various possible factors including representativeness and the observation operators (Table 3 , the middle column). For reference, the measurement errors in the actual instrument specifications are also shown in the right column of Table 3 .

\section{d. Observation scenarios}

We investigate three scenarios to evaluate the impact of dense and frequent surface DA, and the list of the main series of the LETKF experiments are shown in Table 4a. The control experiment (CTRL) assimilated only PAWR data. Two other experiments assimilated both PAWR data and surface data. The S8 experiment assumed the existing sites ( 8 points, blue dots in Fig. 1), and the S167 experiment additionally

Table 3. The observed variable and error standard deviations.

\begin{tabular}{|c|c|c|}
\hline Observed variable & $\begin{array}{l}\text { Observation error standard deviation } \\
\text { for simulated observations }\end{array}$ & $\begin{array}{l}\text { Measurement error standard deviation } \\
\text { in the instrument specifications }\end{array}$ \\
\hline \multicolumn{3}{|c|}{ PAWR at Osaka university Suita campus } \\
\hline Radar reflectivity & $\begin{array}{l}10 \% \text { (fixed } 2 \mathrm{dBZ} \text { when it is smaller } \\
\text { than } 20 \mathrm{dBZ} \text { ) }\end{array}$ & $2 \mathrm{dBZ}$ \\
\hline Radial wind & $3 \mathrm{~m} \mathrm{~s}^{-1}$ & $1.5 \mathrm{~m} \mathrm{~s}^{-1}$ \\
\hline \multicolumn{3}{|c|}{ Surface observation (POTEKA II) } \\
\hline Horizontal wind components $(\mathrm{u}, \mathrm{v})$ & $50 \%\left(\right.$ minimum $\left.2 \mathrm{~m} \mathrm{~s}^{-1}\right)$ & $\pm 1 \mathrm{~m} \mathrm{~s}^{-1}$ \\
\hline Relative humidity & $10 \%$ & $\pm 5 \%$ \\
\hline Temperature & $1 \mathrm{~K}$ & $\pm 0.5 \mathrm{~K}$ \\
\hline Pressure & $1 \mathrm{hPa}$ & $\pm 0.5 \mathrm{hPa}$ \\
\hline
\end{tabular}


Table 4. List of experiments.

(a) The main series of experiments

\begin{tabular}{cl}
\hline Experiment & \multicolumn{1}{c}{ Observational data } \\
\hline CTRL & PAWR Only \\
S8 & PAWR $+\mathbf{8}$ surface stations \\
S167 & PAWR $+\mathbf{1 6 7}$ surface stations \\
NO-DA & None \\
\hline
\end{tabular}

(b) The sensitivity experiments

\begin{tabular}{cl}
\hline Experiment & \multicolumn{1}{c}{ Observational data } \\
\hline Ps & PAWR +167 surface pressure \\
UVs & PAWR +167 surface wind \\
RHs & PAWR +167 surface relative humidity \\
Ts & PAWR +167 surface temperature \\
\hline
\end{tabular}

included all other Kobe city elementary schools (167 points, blue and red dots in Fig. 1). At each LETKF step, approximately 400,000 PAWR data were input for assimilation. In addition, 835 (40) surface data were available in S167 (S8), only $0.2 \%(0.01 \%)$ of the PAWR data. To investigate the impact of DA and an influence from the boundary condition, an experiment without DA (NO-DA) was also performed.

We also performed sensitivity experiments of S167 to find the relative importance of each observed variable. Here, every single variable, such as horizontal winds, pressure, relative humidity, and temperature, was assimilated separately. The list of the experiments is summarized in Table $4 \mathrm{~b}$.

\subsection{Forecast experiments}

To investigate the impact of surface DA on forecasts, we perform 30-minute forecast experiments at 1-km resolution (Domain 2) by JMA-NHM, initialized by the ensemble mean analyses at 0300 UTC (after 30 cycles), 0310 UTC (after 40 cycles), and 0320 UTC (after 50 cycles). Numerical model settings are the same as the nature run at $1-\mathrm{km}$ resolution.

\subsection{Verification method}

To verify the analyses and forecasts, we take the difference from the nature run. Here, the nature run at $100-\mathrm{m}$ resolution is reduced to $1-\mathrm{km}$ resolution by averaging the 10-by-10 pixels for each 1-km pixel. This way, we obtain the differences between the experimental results and the nature run with $1-\mathrm{km}$ resolution. The differences from the nature run are considered as the errors, so that we can compute the root mean square errors (RMSEs) and the ensemble spread at $1-\mathrm{km}$ resolution. For the domain average, we (a) RMSE and Ensemble spread $\left(\mathrm{Qv} ; z^{*}=2 \mathrm{~km}\right)$ NO-DA and CTRL

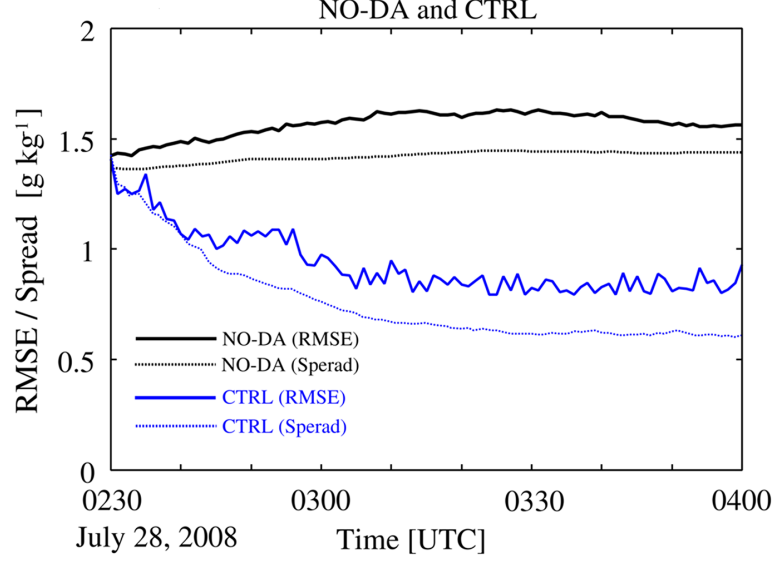

(b) Ensemble spreads in all cases $\left(\mathrm{Qv} ; z^{*}=2 \mathrm{~km}\right)$

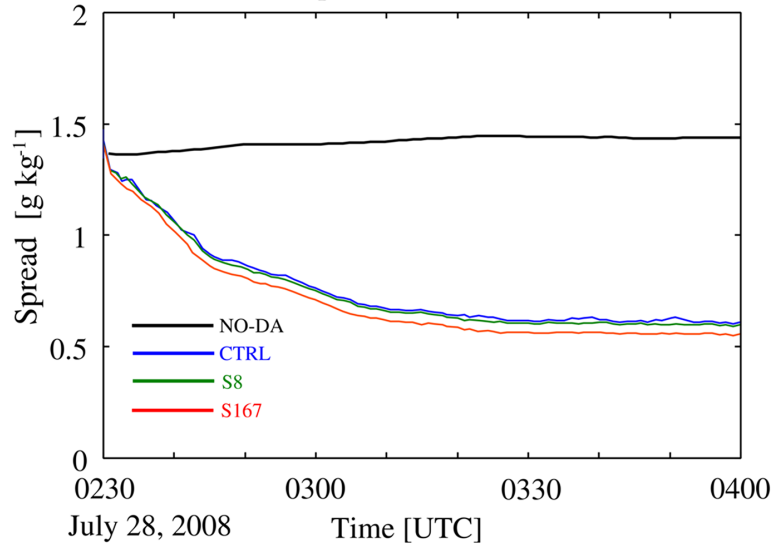

Fig. 7. (a) Time series of RMSE for water vapor mixing ratio $\left[\mathrm{g} \mathrm{kg}^{-1}\right]$ at $z^{*}=2 \mathrm{~km}$ (solid line) and the ensemble spread $\left[\mathrm{g} \mathrm{kg}^{-1}\right]$ (dashed line). Black and blue lines show NO-DA and CTRL experiments, respectively. (b) Time series of ensemble spreads of NO-DA (black line), CTRL (blue line), S8 (green line), and S167 (red line).

take the entire model domain for the nature run of the size $120 \mathrm{~km}$-by-120 km (Domain 4). We consider the ensemble mean fields as the best theoretical estimate and focus on the ensemble mean fields for verification. Hereafter, the nature run refers to the averaged nature run fields at $1-\mathrm{km}$ resolution unless otherwise noted.

\section{Results}

\subsection{General performance of the LETKF system}

To investigate the general performance of the LETKF system, Fig. 7a shows the time series of the analysis RMSE and ensemble spread for water vapor 
Mixing ratio of water vapor at $z^{*=2} \mathrm{~km}$ (after the first cycle of LETKF) $\quad\left[\mathrm{g} \mathrm{kg}^{-1}\right.$ ]
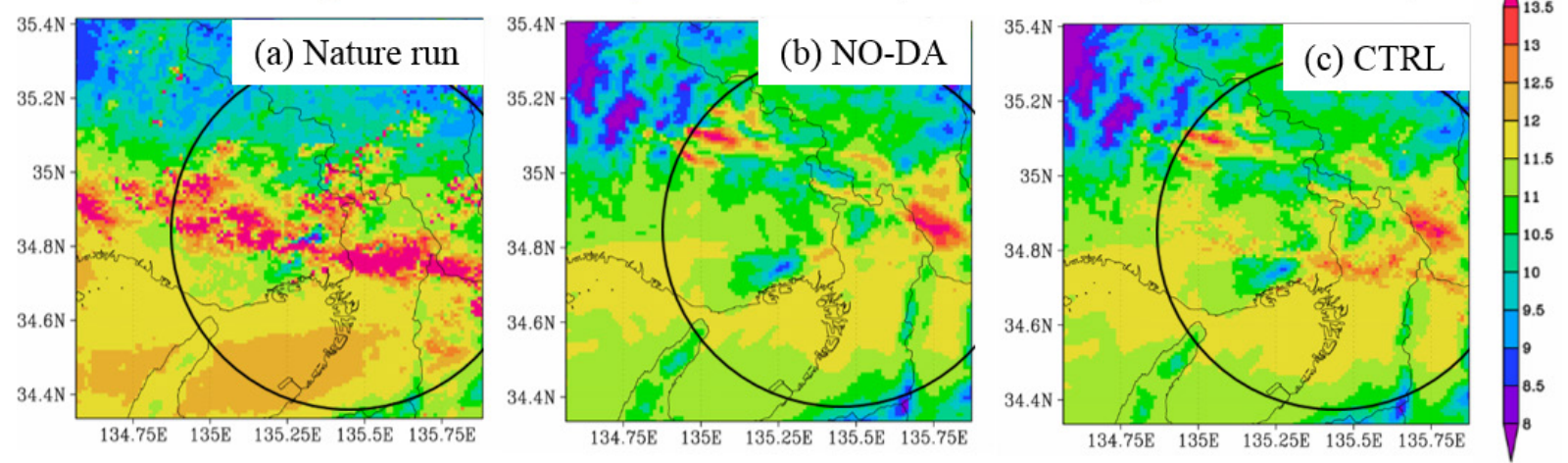

Fig. 8. Water vapor mixing ratio $\left[\mathrm{g} \mathrm{kg}^{-1}\right]$ at $z^{*}=2 \mathrm{~km}$ for (a) nature run, (b) NO-DA, and (c) CTRL at $0231 \mathrm{UTC}$ after the first analysis. Black circles indicate the observational range of the PAWR.
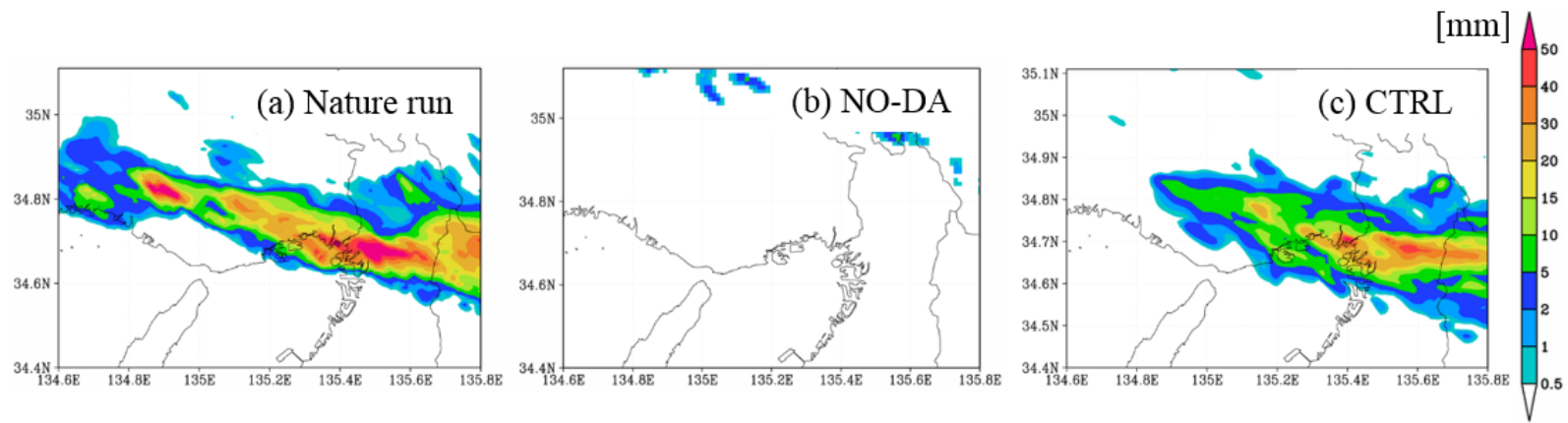

Fig. 9. Accumulated rainfall amount from 0310 UTC to 0400 UTC [mm] for (a) nature run, (b) NO-DA, and (c) CTRL.

mixing ratio at the 2-km level of the JMA-NHM's terrain following vertical coordinate $\left(z^{*}=2 \mathrm{~km}\right.$, see Saito et al. 2006 for the definition). This measure is chosen because water vapor in the lower troposphere is strongly related to precipitation. The RMSE drops rapidly by assimilating the PAWR data (blue full line). After repeating 40 cycles of the LETKF (0310 UTC), the RMSE reaches to the asymptotic level about a half of NO-DA (black full line). Although only radar reflectivity and Doppler velocity were assimilated, we find clear improvements in the moisture fields. The ensemble spread also shows a similar drop (blue dashed line). Figure $7 \mathrm{~b}$ shows the time series of the ensemble spread in all four experiments. With more observations, the ensemble spread becomes smaller. Overall, the results suggest that the LETKF system performs stably with 40 ensemble members. The ensemble spread of NO-DA is nearly flat (black broken line), so that the unperturbed boundary conditions have a limited impact in this case study.

\subsection{Control experiment (CTRL)}

To investigate the impact of the PAWR DA at the first analysis, Fig. 8 shows the water vapor mixing ratio at $z^{*}=2 \mathrm{~km}$ at $0231 \mathrm{UTC}$ after the first analysis. The nature run shows moist areas corresponding to well-developed convections from west to east near $34.8 \mathrm{~N}$ (Fig. 8a). NO-DA, or the first guess, underestimates moisture (Fig. 8b), but CTRL shows rainfall and moist areas extended from $34.5 \mathrm{~N}$ to $35.0 \mathrm{~N}$, closer to the nature run (Fig. 8c).

Figure 9 shows the accumulated rainfall amount from 0310 UTC (40 cycles after the spin-up) to 0400 UTC (90 cycles). In NO-DA, the main convective line is completely missing (Fig. 9b). By contrast, CTRL shows precipitation patterns corresponding to the main convective line (Fig. 9c). Although the precipitation amount was underestimated, it captures peak values over $50 \mathrm{~mm} \mathrm{~h}^{-1}$. Even though the LETKF experiment employs the reduced-resolution model, PAWR DA was generally effective to simulate the main convec- 
tive rainband.

\subsection{Impacts of surface data (S8 and S167)}

We now investigate the impact of the surface observation data in addition to the PAWR data (Table 4). Figures 10 and 11 show the side-by-side comparisons of the nature run, NO-DA, and three LETKF experiments (CTRL, S8, and S167) at the lowest model level $\left(z^{*}=20 \mathrm{~m}\right)$ after 45 cycles of LETKF $(0315$ UTC). First, we focus on rain mixing ratio around (34.7 N, 135.3 E) (Fig. 10, black ellipses) corresponding to the disaster site. The peak value of rain mixing ratio in $\mathrm{S} 167$ reaches more than $5 \mathrm{~g} \mathrm{~kg}^{-1}$, similar to the nature run, although the heavy rain area is slightly reduced.
This is likely related to the resolution degradation from the nature run at $100-\mathrm{m}$ resolution. S8 has an improvement in rain mixing ratio compared with CTRL, but it is considerably smaller than S167. NO-DA shows no rain at all. Figure 11 shows the near-surface divergence fields. Shoji et al. (2009) and Kusabiraki et al. (2011) pointed out that a strong convergence zone was extended along the leading edge of the convective line, and it is a noteworthy feature tied to the heavy rainfall. The nature run shows the strong convergence zone clearly (Fig. 11a, black ellipse). CTRL shows some of this feature from the PAWR data (Fig. 11c), and it is improved in S8 and S167 (Figs. 11d, e). In S167, the convergence zone extends
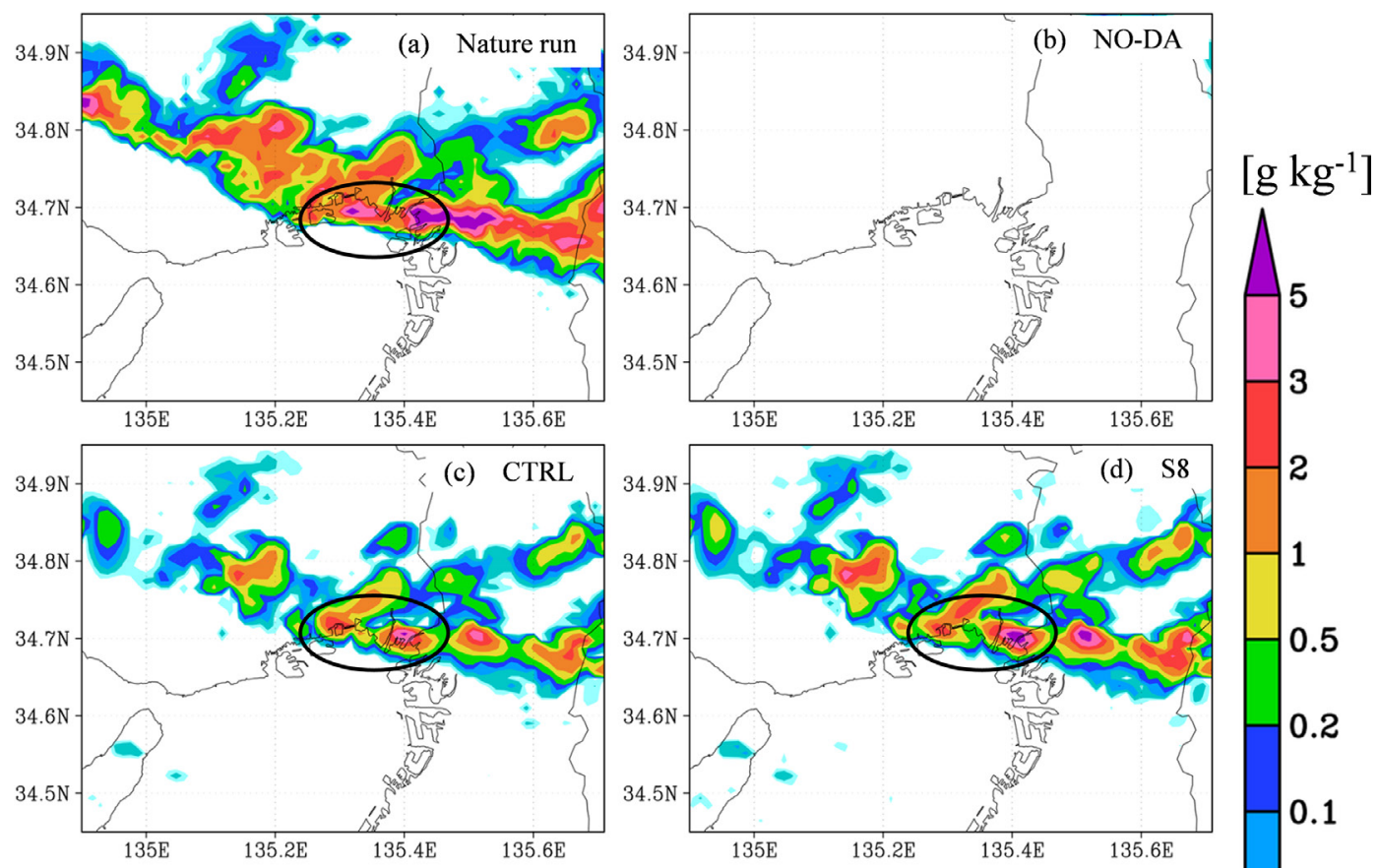

2
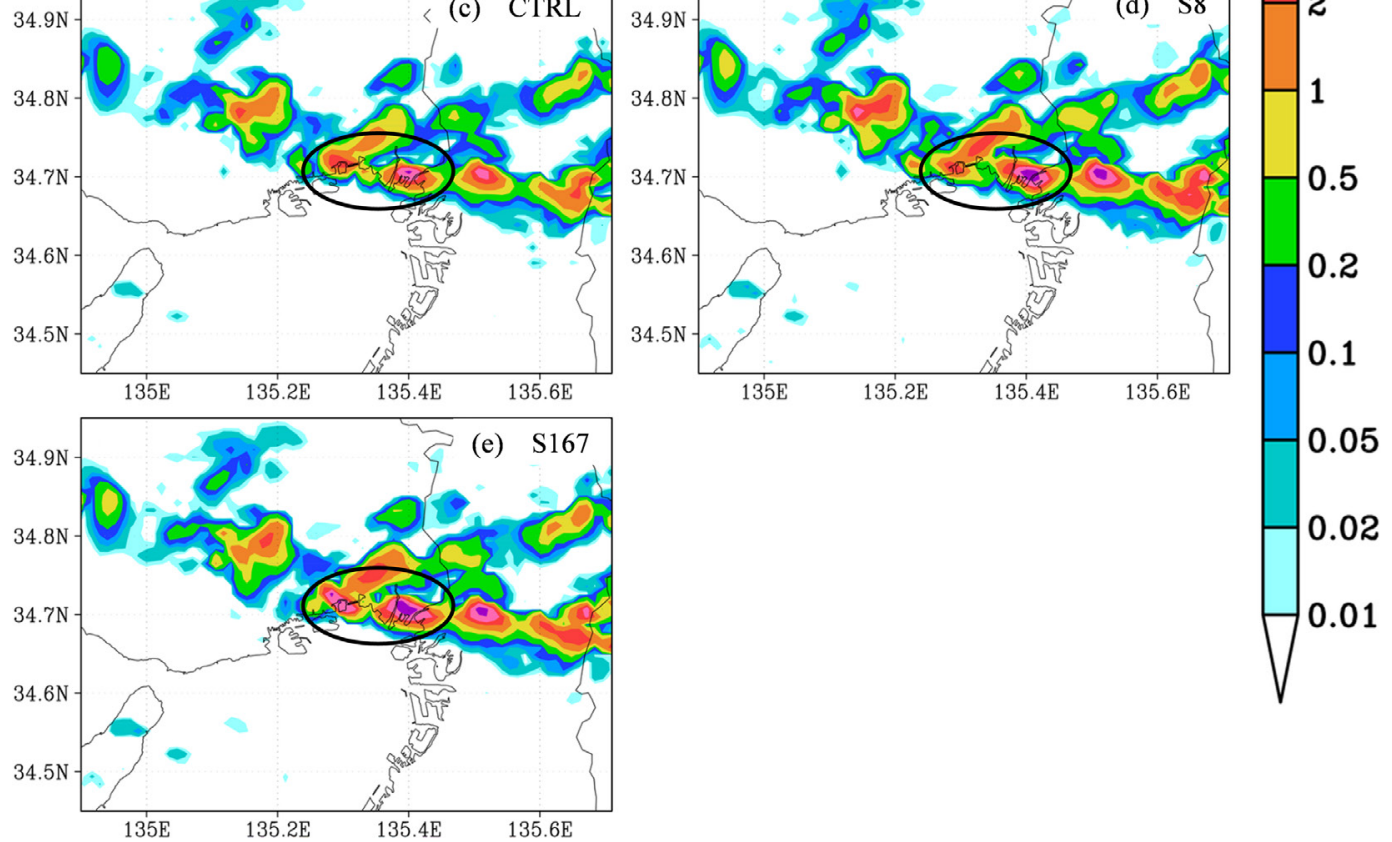

Fig. 10. Rain mixing ratio $\left[\mathrm{g} \mathrm{kg}^{-1}\right]$ at the lowest model level $\left(z^{*}=20 \mathrm{~m}\right)$ at $0315 \mathrm{UTC}$ after 45 LETKF cycles for (a) nature run, (b) NO-DA, (c) CTRL, (d) S8, and (e) S167. White and black dots indicate the locations of the 167 stations, where white dots indicate the existing 8 POTEKA II stations. Black ellipses show the disaster site. 
in the northwest direction compared with the other experiments (Fig. 11), better matching with the nature run (Figs. 11a, e).

So far, we have found that the surface data had a significant impact although the observations stick to the ground, and the data size is only a tiny fraction compared with the PAWR data. To investigate how the impact of the surface data propagates horizontally and vertically in time, the evolution of the differences of equivalent potential temperature (EPT) and winds is investigated. Figure 12 shows the differences between CTRL and S167 and between CTRL and S8. At 0231 UTC after the first analysis cycle (Fig. 12a1), the EPT differences spread widely in the horizontal, corresponding to the observation distribution (Fig. 1). The vertical impact extends up to approximately 1500 $\mathrm{m}$ high as limited by the vertical localization. As the LETKF cycle progresses, the area of large EPT analysis increments is concentrated around $(34.7 \mathrm{~N}, 135.3$ E) (Figs. 12a2-a4), corresponding to the improvement of rain mixing ratio (Fig. 10c). We also find a large impact on horizontal winds, so that the convergence is enhanced. The vertical signals also extend to higher levels as the LETKF cycle progresses. The area of large EPT analysis increments was propagated to upper levels with intensified upward motion approximately $135.3 \mathrm{E}$, where the intensive rain occurs. S8 shows generally similar improvements although in a narrower region and with smaller amplitudes (Fig. $12 b)$. The narrower region after the first cycle (Fig. 12b1) corresponds to the observational sites for S8 (Fig. 1, blue).
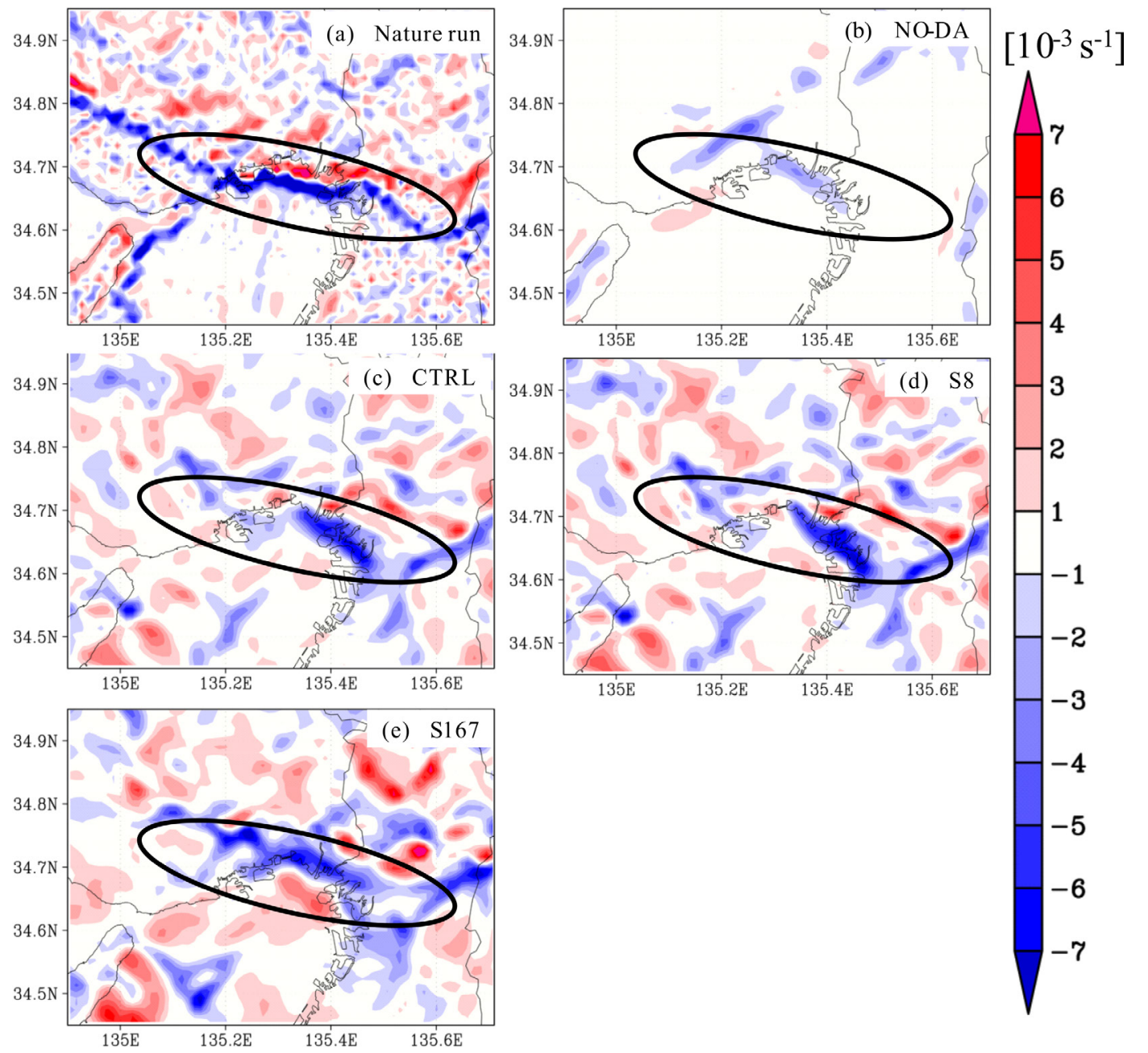

Fig. 11. Similar to Fig. 9, but for divergence $\left[10^{-3} \mathrm{~s}^{-1}\right]$. Black ellipses show the strong convergence zone. 
(a) S167-CTRL
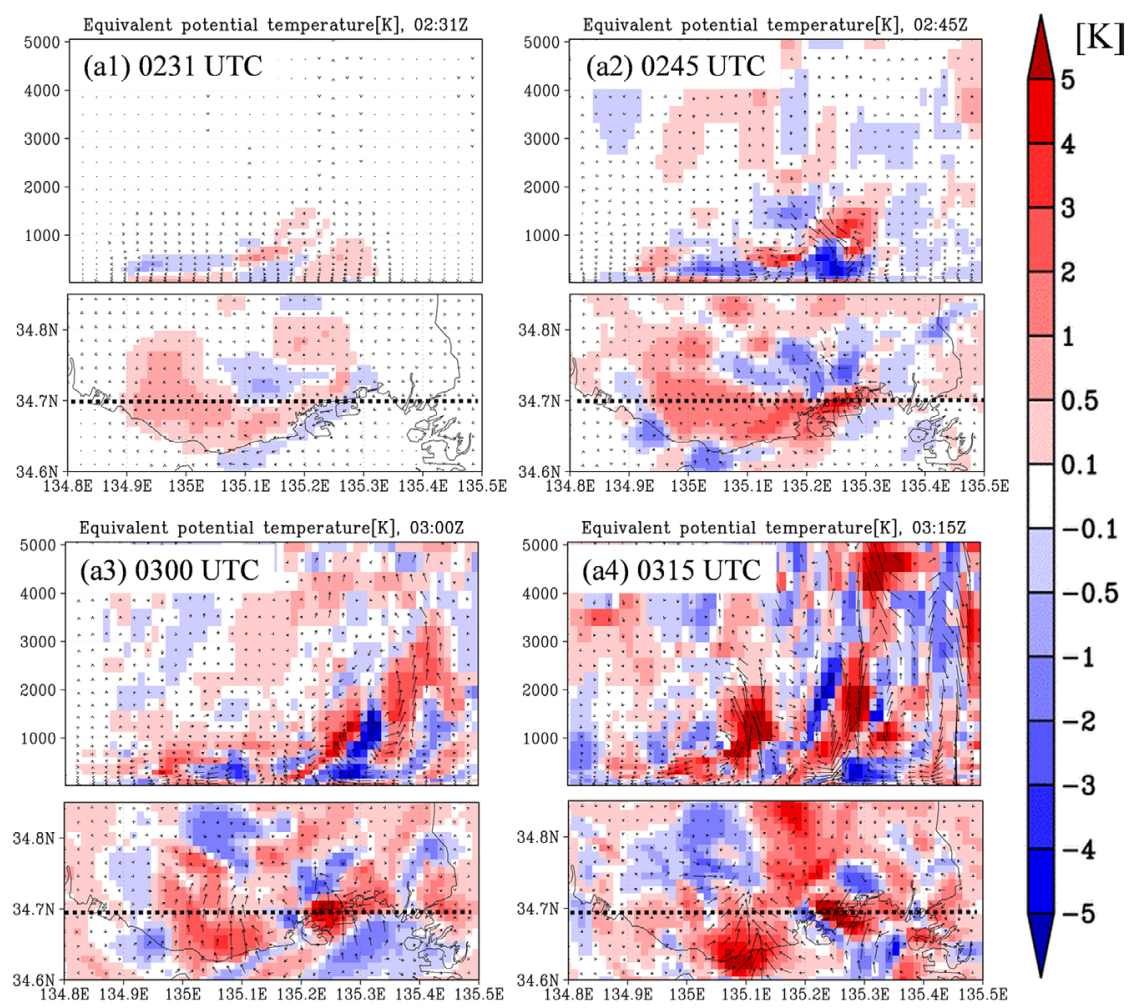

(b) S8 - CTRL
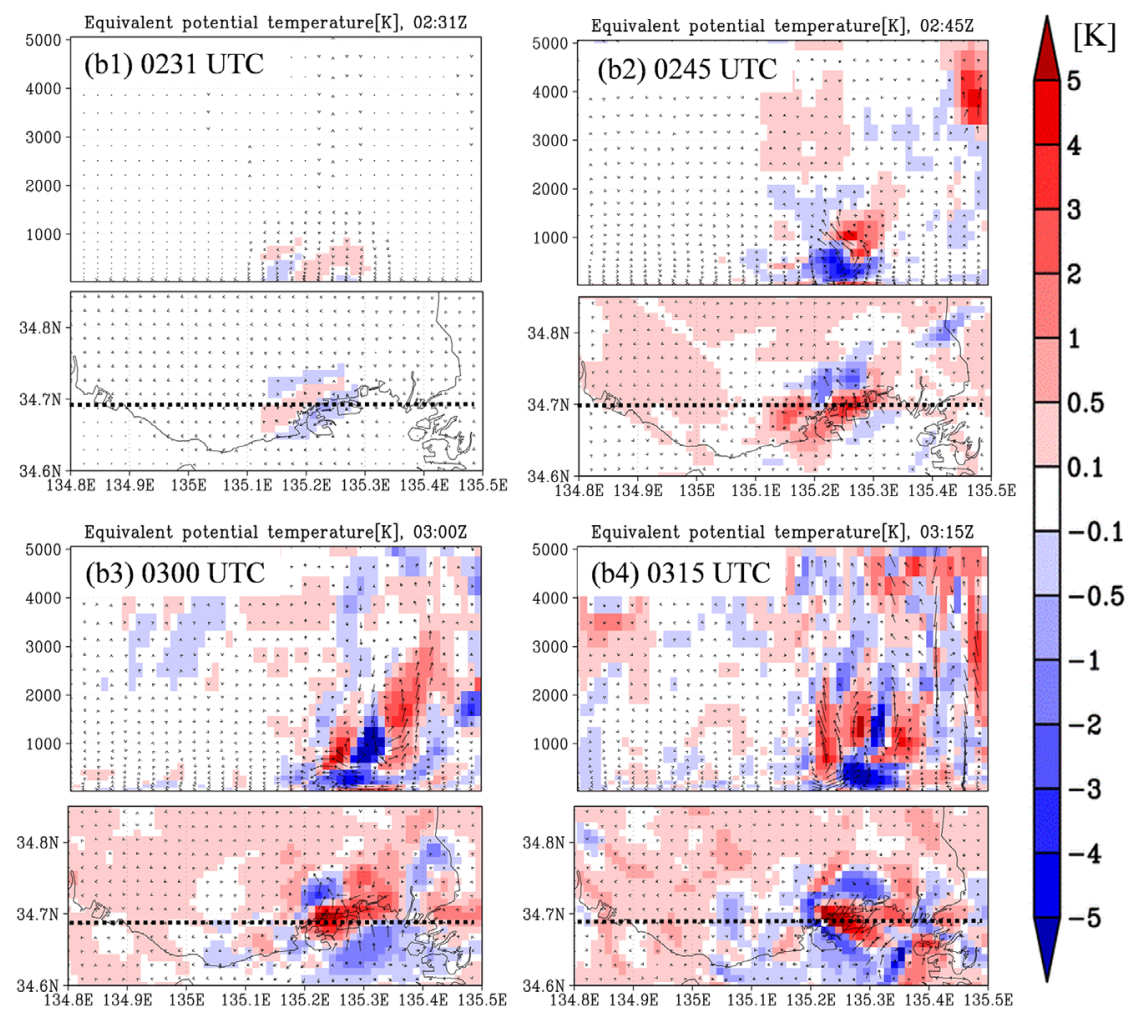

$[\mathrm{K}]$

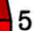

3

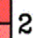

1

0.5

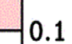

Fig. 12. (a) Differences of equivalent potential temperature $[\mathrm{K}]$ and wind velocity between S167 and CTRL at 0231 UTC (after first cycle of LETKF), 0245 UTC (15 cycles), 0300 UTC (30 cycles), and 0315 UTC (45 cycles). Lower panels show the results at the lowest model level $\left(z^{*}=20 \mathrm{~m}\right)$, and upper panels show the vertical cross-section at the black dashed lines. Vertical wind is enlarged by a factor of 3. (b) Similar to (a), but for the differences between S8 and CTRL. 

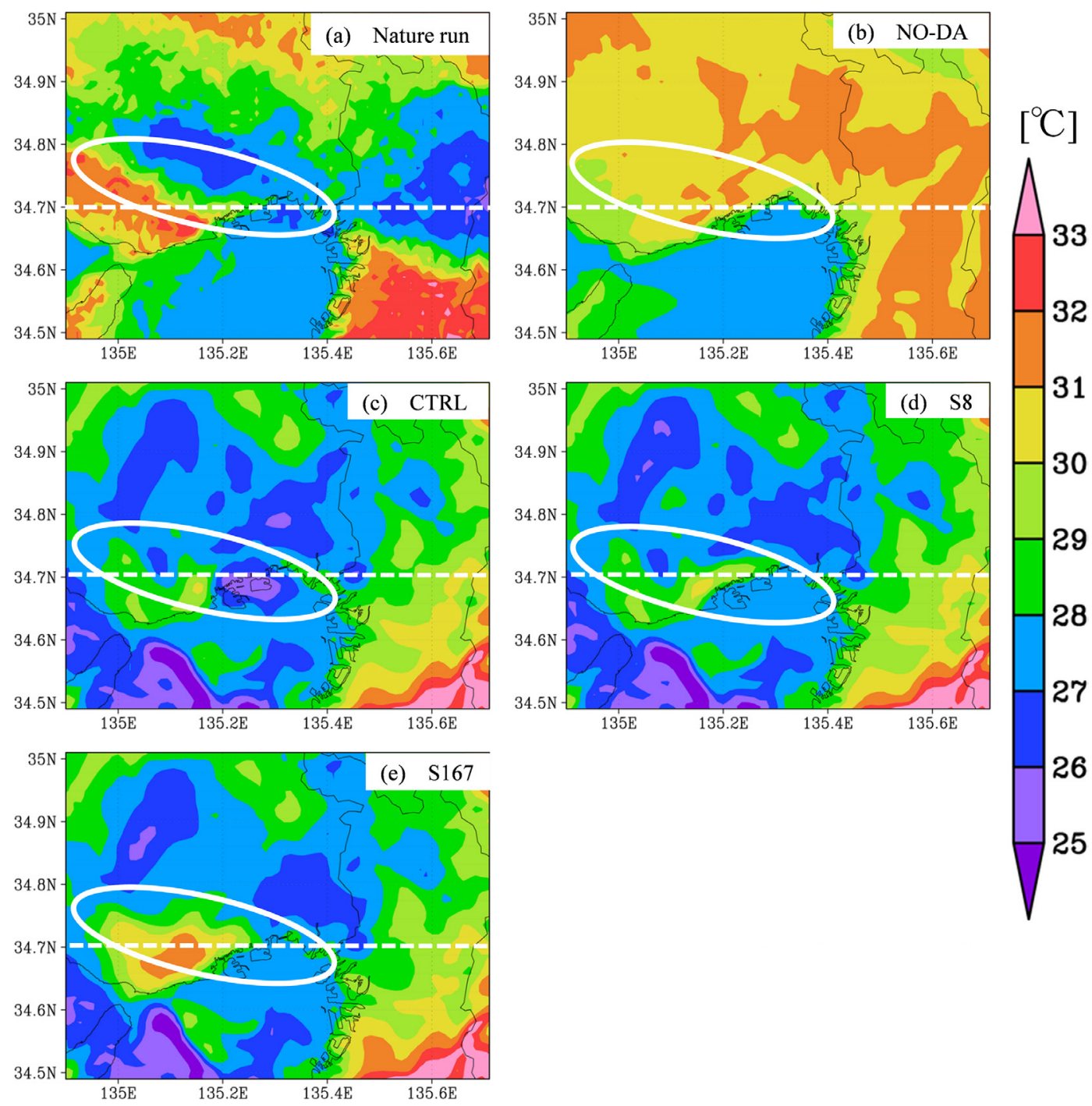

Fig. 13. Mean-sea-level temperature at 0315 UTC (after 45 cycles of LETKF) for (a) nature run, (b) NO-DA, (c) CTRL, (d) S8, and (e) S167. White and black dots indicate the locations of the 167 stations, where white dots indicate the existing 8 POTEKA II stations. White ellipses show the large temperature gradient zone. Dashed lines denote $34.7 \mathrm{~N}$ latitude that corresponds to the vertical cross-sections in Figs. 14 and 15.

Figure 13 shows the mean-sea-level temperature at 0315 UTC (after 45 cycles of LETKF). The lowest model level temperature is corrected to the meansea-level by assuming the atmospheric lapse rate of $6.5 \mathrm{~K} \mathrm{~km}^{-1}$. Compared with NO-DA, CTRL became closer to the nature run. Additional surface observations improve the surface temperature field (Figs. 13c, d, e). As Shoji et al. (2009) and Kusabiraki et al. (2011) pointed out, the large temperature gradient in the north-south direction is a main feature at the leading edge of the convective line, as highlighted by the black ellipses in Fig. 11.

The fine temperature gradient provided major improvements in the vertical structure around the main rainfall area. Figures 14 and 15 show the zonal-vertical cross-sections of EPT, zonal-vertical wind, and rain mixing ratio at $34.7 \mathrm{~N}$, the center of the convective cells of our interest, as shown by the dashed lines in Fig. 13. In all cases, EPT is generally decreasing with height below $3 \mathrm{~km}$, so that the stratification is convectively unstable (Fig. 14). However, the vertical motion is quite different especially between the nature 

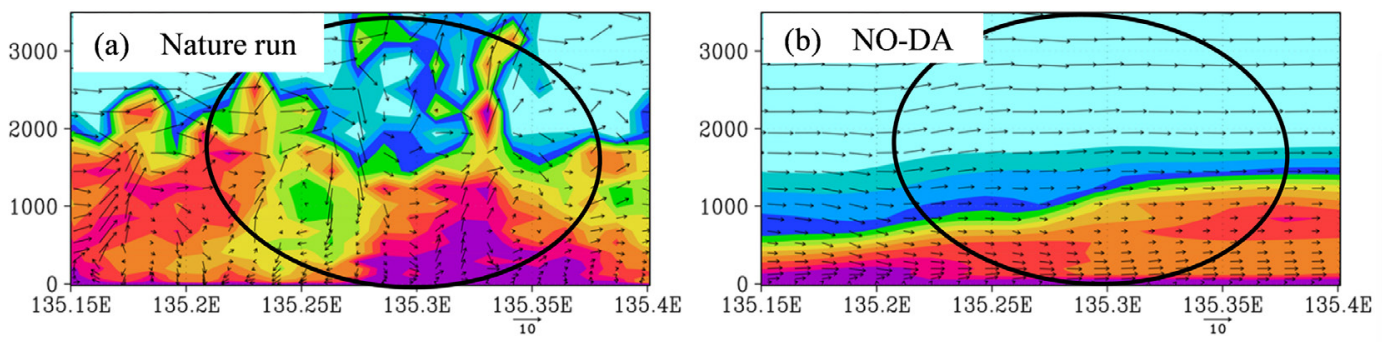

$[\mathrm{K}]$
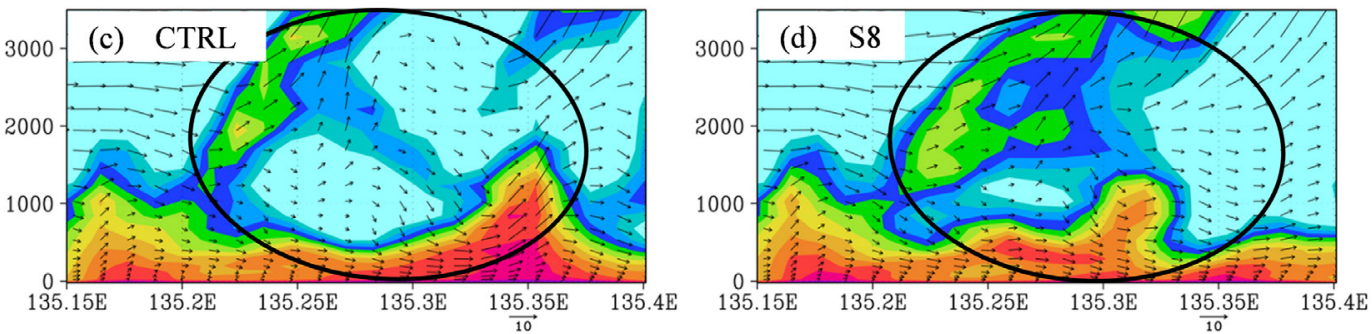

350

349

348

347

346

345

344

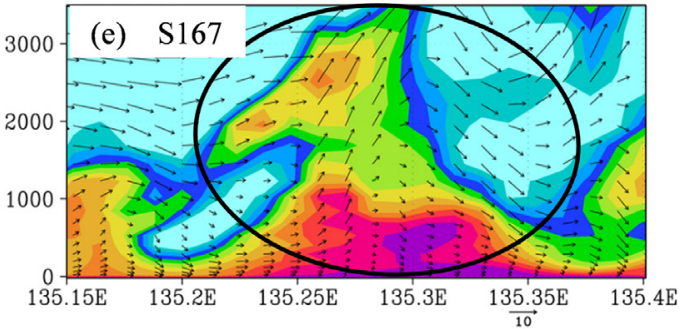

Fig. 14. Zonal-vertical cross-section of equivalent potential temperature [K] (shades) and zonal-vertical wind [ $\left.\mathrm{m} \mathrm{s}^{-1}\right]$ (vectors) at $34.7 \mathrm{~N}$ at $0315 \mathrm{UTC}$ (after 45 cycles of LETKF) for (a) nature run, (b) NO-DA, (c) CTRL, (d) S8, and (e) $\mathrm{S} 167$. Vertical wind is presented with triple size.

run and NO-DA (Figs. 14a, b). The nature run shows an intense upward motion, enhancing the convective development (Fig. 14a). In NO-DA, in contrast, the vertical motion is very weak and unfavorable to initiate convective activities even if the stratification is convectively unstable (Fig. 14b). In CTRL, the vertical motion was clearly improved from NO-DA (Fig. 14c) and was effective to generate a convection located approximately $135.32 \mathrm{E}$. By assimilating the surface observations, EPT near the surface was increased, and S8 and S167 showed more convectively unstable stratifications than CTRL (Figs. 14c, d, e). The improvement of the surface conditions contributed to the favorable environment for convective developments. In response to EPT and upward motion, rain mixing ratio was also intensified (Fig. 15). In S167, the peak value for rain mixing ratio was over $2 \mathrm{~g} \mathrm{~kg}^{-1}$, very similar to the nature run. In CTRL and S8, the distributions of rain mixing ratio were similar to that of S167, but the values were a half or less.

\subsection{Forecast experiments}

It is expected that the improved initial condition would contribute to improve the subsequent forecast accuracy. Figure 16 shows the RMSE of water vapor mixing ratio at $z^{*}=2 \mathrm{~km}$, similarly to Fig. 7 . The black and blue full lines are the same as those of Fig. 7 , and red and blue dashed lines denote the forecast experiments. As we have seen, S167 (red full line) is superior to CTRL, so that the analysis RMSE was reduced by approximately $0.08 \mathrm{~g} \mathrm{~kg}^{-1}$ or $10 \%$ improvement. The improvement generally persists in the forecasts; the RMSEs of S167 are consistently lower than those of CTRL, particularly in the first 30 minutes. After 30-minute forecasts, the advantage of S167 becomes smaller. Compared with NO-DA, forecasts are skillful for an hour, although the skill is decreased rapidly. We notice that all three forecasts show rapid error growths in the initial 5 to 10 minutes, and after that, the error growths become slower.

Figures 17 and 18 show the side-by-side comparisons of the nature run and the forecasts initialized by 

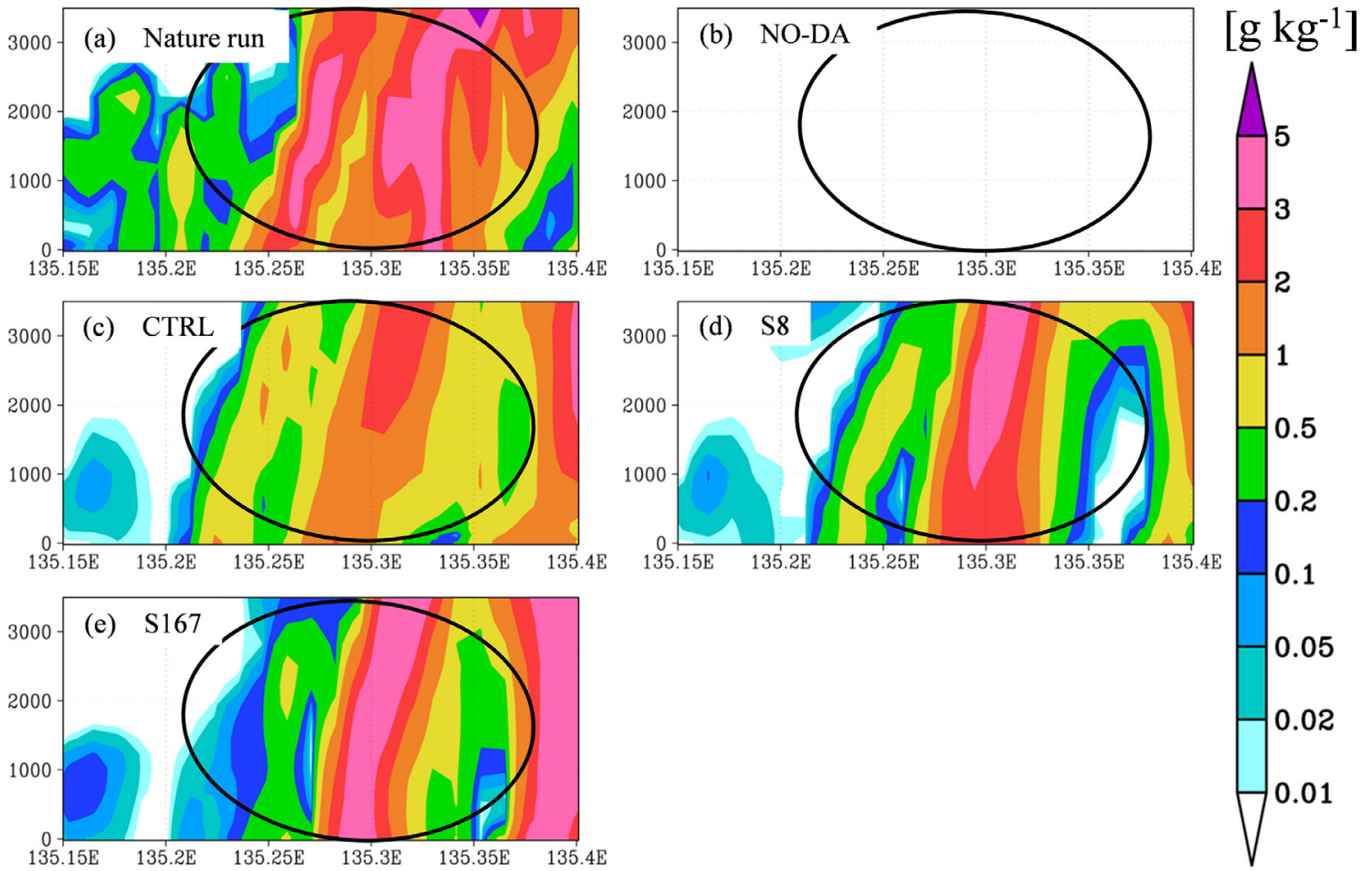

Fig. 15. Similar to Fig. 14, but for rain mixing ratio $\left[\mathrm{g} \mathrm{kg}^{-1}\right]$. NO-DA indicates no rain, $<0.001 \mathrm{~g} \mathrm{~kg}^{-1}$.

the three LETKF experiments (CTRL, S8, and S167) at 0320 UTC. Figure 17 shows the rain mixing ratio at the lowest model level $\left(z^{*}=20 \mathrm{~m}\right)$ at 0330,0340 , and 0350 UTC (10-, 20-, and 30-minute forecasts). Here, we focus on convections in the black circled area in Fig. 17. As the surface observation density increases, rain mixing ratio becomes more intense. In the 30minute forecasts (0850 UTC), the peak value of rain mixing ratio reaches $2 \mathrm{~g} \mathrm{~kg}^{-1}$ in S167, consistent with the nature run. By contrast, it is only less than $10 \%$ of the nature run in CTRL (Figs. 17a, c, d).

Figure 18 shows the vertical cross-sections of mixing ratio of cloud water, rain, cloud ice, snow, and graupel at the center of the convection of our interest (black dashed lines in Fig. 18). S167 shows three active convections at 0330 UTC (A, B, and C in Fig. 18c-10). Among them, the convection B developed, and its cloud top reached over $10-\mathrm{km}$ altitude at 0350 UTC (Figs. 18c-20, c-30). The location and peak values of rain mixing ratio and upward motion are similar to those of the nature run. S8 also shows a similar convection (Figs. 18b-10, b-20), but in a narrower region and with smaller mixing ratio (Fig. 18b-30). In CTRL, although the convection is gene-

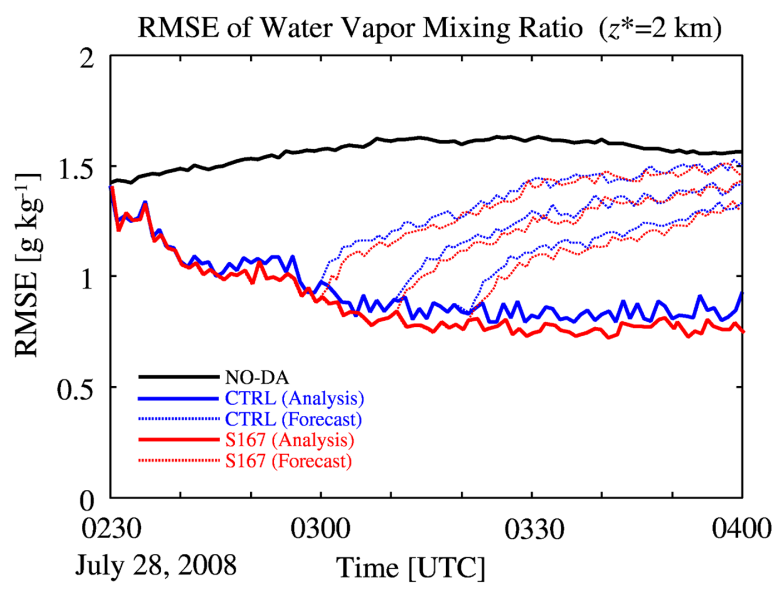

Fig. 16. Time series of RMSE for water vapor mixing ratio $\left[\mathrm{g} \mathrm{kg}^{-1}\right]$ at $z^{*}=2 \mathrm{~km}$. Black, blue, and red lines correspond to NO-DA, CTRL, and S167, respectively. Full and broken lines show the analysis and forecast RMSE, respectively. 


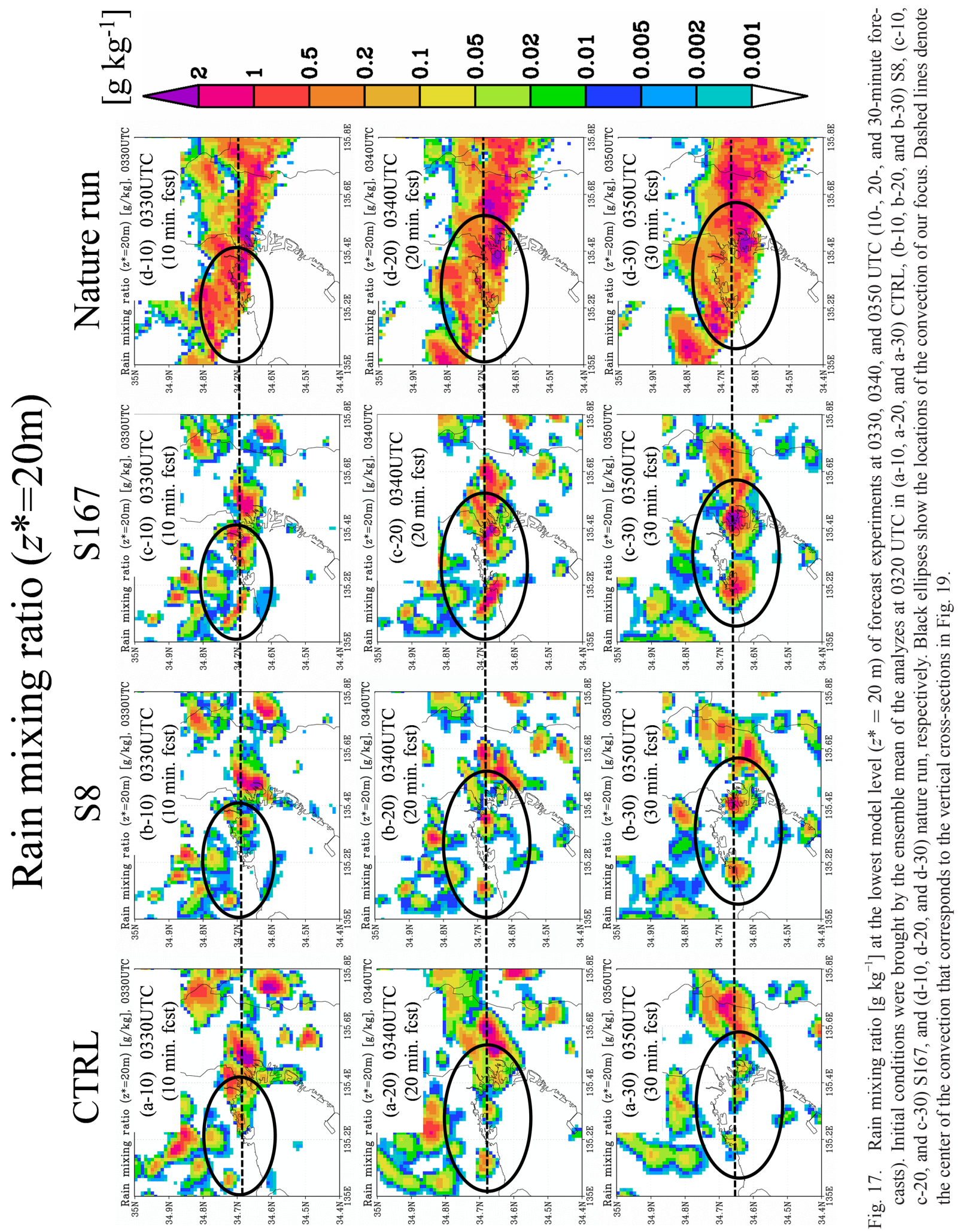




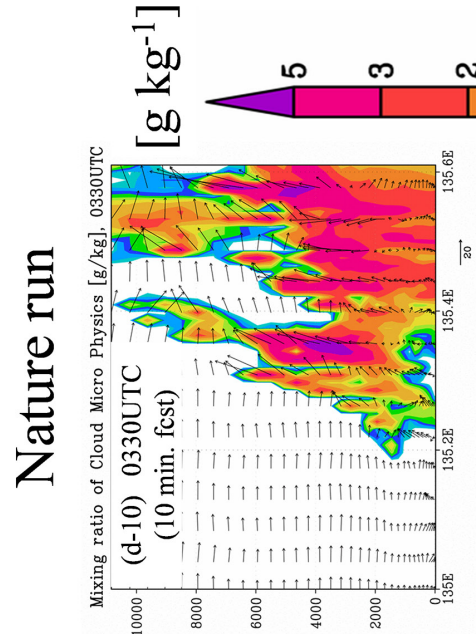

\section{బ}
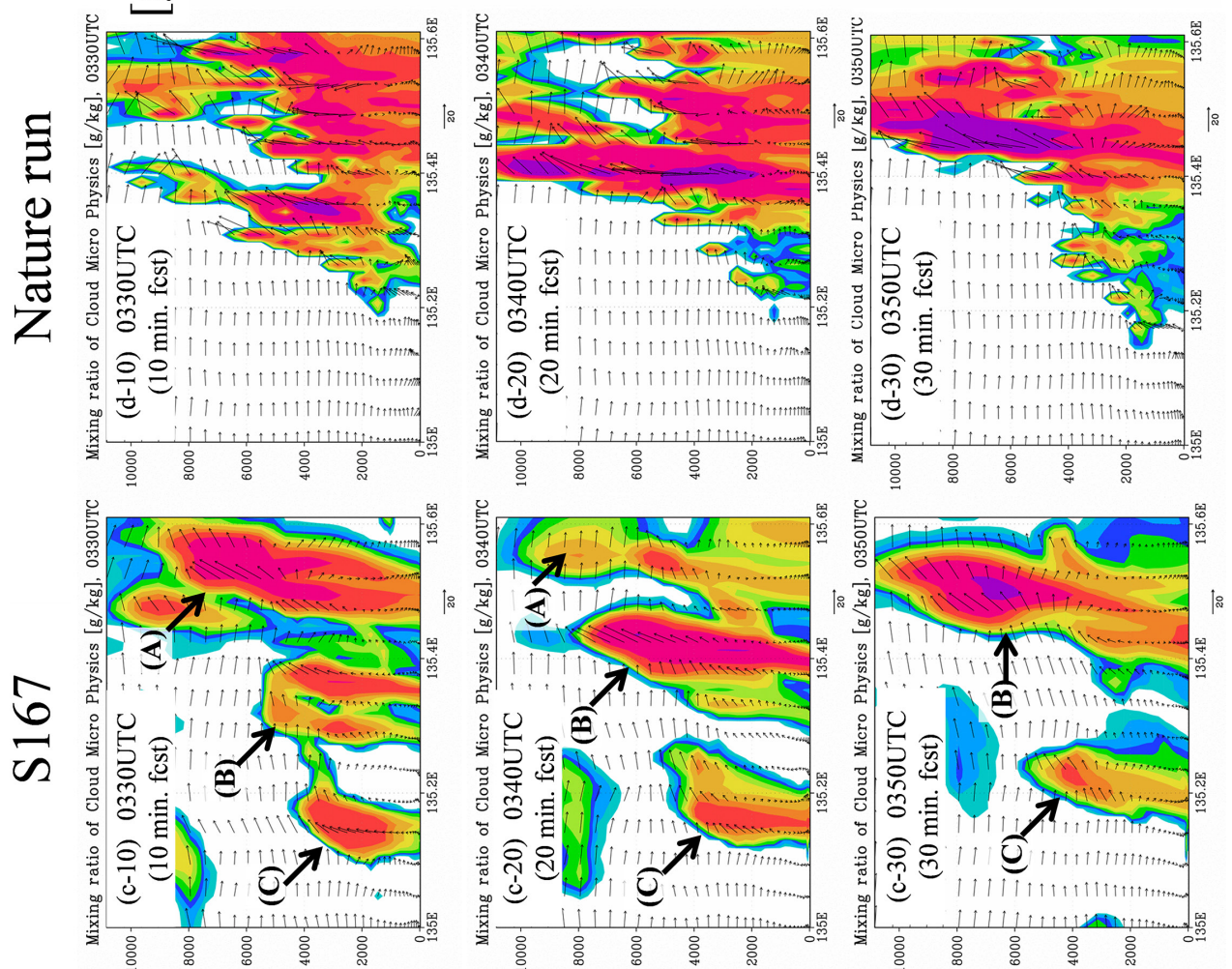

i̊으

के ट⿱宀㠯

$\stackrel{\vec{\sigma}}{=}$

ชิ

에 $\frac{6}{4}$

芩

해 믈

चี

क 0

లं

苛

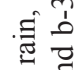

馬

1

을

फ

윰 릅

응

.

퓽
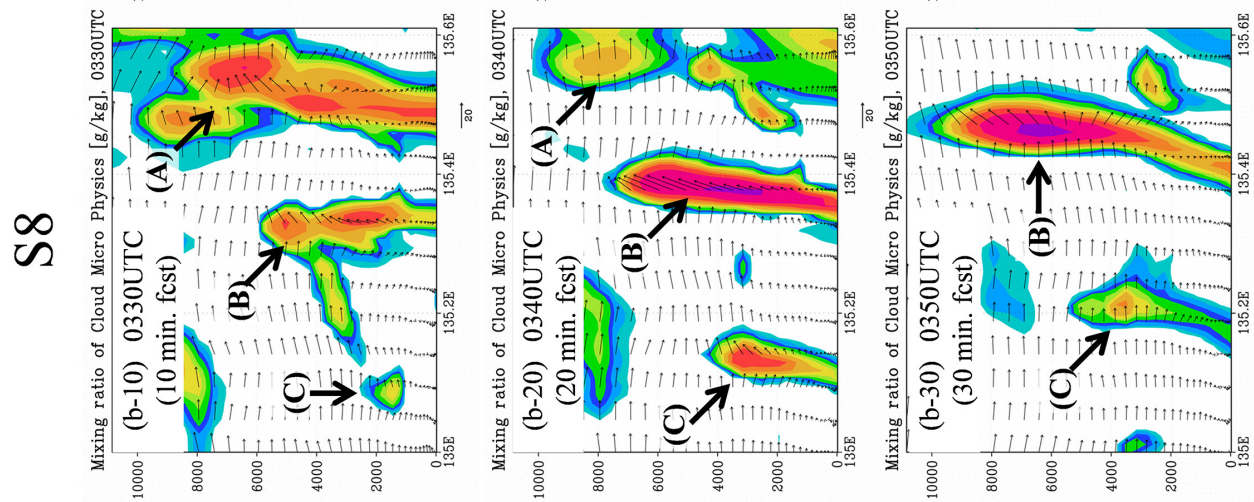

ㅇํㅇ

둔

滒恖

.ઇ ప్ర

焉

$\infty$
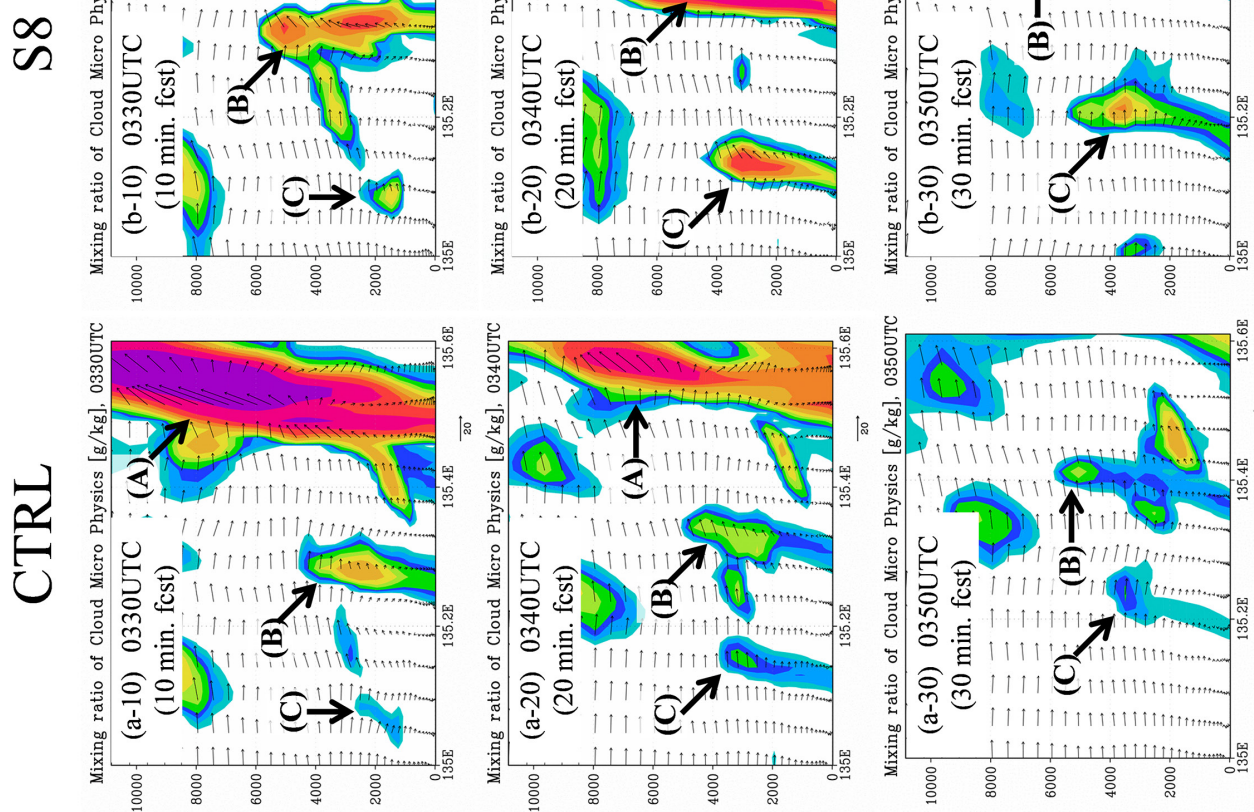

要

逑

를

喝氙

흐름

过

号

莺导䓌

융ํㅇ

ㅋํㅇ ?

을 흐

$\infty \stackrel{0}{0} \stackrel{0}{0}$

Di 
rated (Figs. 18a-10, a-20), it is significantly weaker and does not develop in the 30-minute forecast period (Fig. 18a-30).

\subsection{Sensitivity experiments}

The results of the sensitivity experiments are summarized in Fig. 19. S167 is the best, so that assimilating all surface variables provides the best results. RHs is the second best probably because relative humidity is related to the lower atmospheric stratification and plays an essential role in developing the upward motion and convective clouds. UVs and Ts also showed better results compared with CTRL. As mentioned in the previous subsection, the horizontal convergence and the temperature gradient near the surface were noticeable features in this rainfall event (Figs. 12, 14). The surface wind and temperature DA contributed to create better conditions in the lower atmosphere. Ps is better than CTRL but shows the smallest impact probably because the local pressure field is relatively less important.

\section{Conclusion}

In this study, we performed a series of OSSEs using the NHM-LETKF at 1-km resolution and with 1-minute update cycles and investigated the potential impact of dense and frequent surface observations on a disastrous rainstorm event in Kobe, Japan on July 28 , 2008. A 100-m-resolution simulation using the JMA-NHM was performed for the nature run, showing important characteristics of the event, such as the precipitation intensity over $100 \mathrm{~mm} \mathrm{~h}^{-1}$, close to the JMA operational radar observation. From the 100-m resolution nature run, both reflectivity and Doppler velocity of PAWR at Osaka University and surface data at 167 locations at all Kobe city elementary schools and R-CCS were simulated for the observations of the OSSEs. In this way, the OSSEs include the model error originated from the different model resolutions.

The control run (CTRL) assimilates the PAWR data only. Although the precipitation intensity was underestimated, the RMSE decreased to be about a half of NO-DA. The two sensitivity experiments with additional surface observations showed that the dense and frequent surface observations had positive impacts on surface temperature, moisture, and convergence, even if the number of surface observations is a tiny fraction of the PAWR data. The surface data increased EPT and enhanced convergent flow along the convection, enhancing favorable atmospheric conditions for convective development. The effect propagated

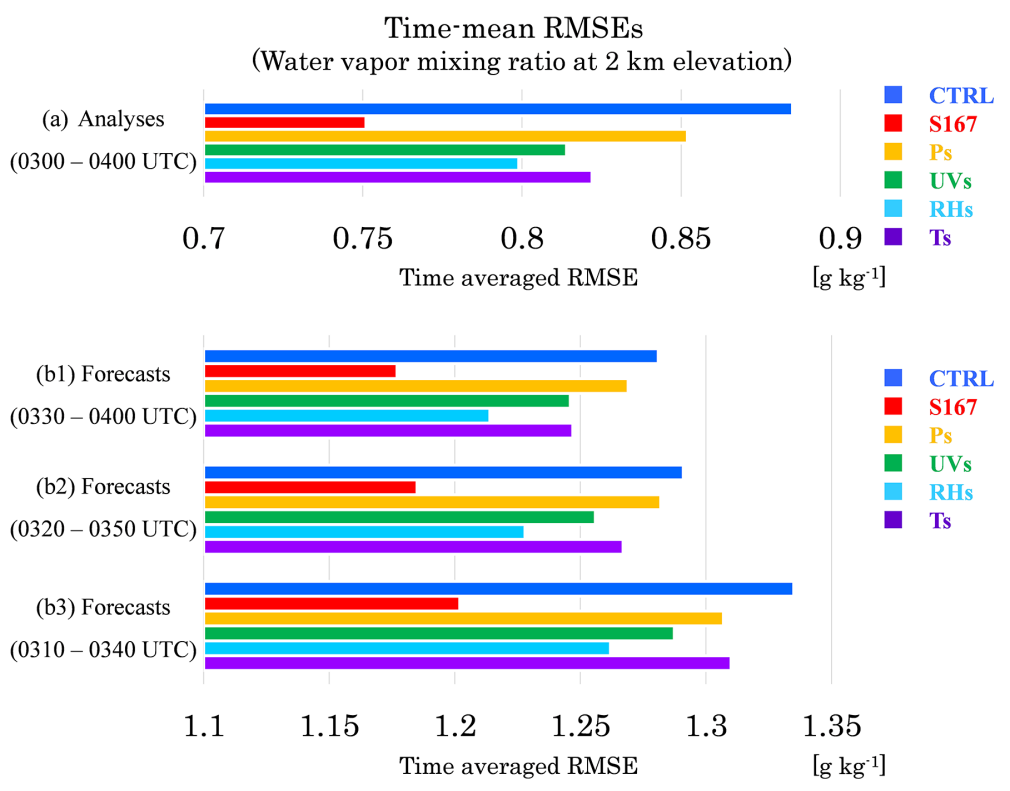

Fig. 19. Time averaged values of the RMSEs of analyses and forecasts for water vapor mixing ratio $\left[\mathrm{g} \mathrm{kg}^{-1}\right]$ at $2 \mathrm{~km}^{-1}$ elevation for (a) analyses from 0300 UTC to 0400 UTC, (b1) 30-minute forecast initialized at 0330 UTC, (b2) at 0320 UTC, and (b3) 0310 UTC. Blue, red, orange, green, light blue, and purple bars indicate the results of CTRL, S167, Ps, UVs, RHs, and Ts, respectively (cf. legend). 
spatially as DA cycles progress, and it enhanced the convective activities with hazardous severe rainfall near River Toga, the actual disaster site. The time series of RMSE in the forecast experiments showed that the improved analysis data contributed to improve the forecasts. S167 showed significantly better results than S8; namely, more surface observations showed larger positive impact.

The results suggest that the surface DA with dense and frequent surface data observed by low-cost instruments potentially be effective to improve the performances of the analyzes and forecasts of severe convective weather. These surface data are relatively smaller in number, but provide important observations about lower atmospheric conditions that are generally more difficult to observe by remote sensing instruments, such as PAWR. A small number of the surface in situ data and a large number of remote sensing data can help each other effectively.

This study performed idealized OSSEs and showed a potential of dense and frequent surface data. To use real surface data, there are potential issues. The inexpensive instrument tends to have quality issues, such as bias and missing data, and using real surface station data is not trivial. An immediate next step would be to use the actual data from the already implemented eight POTEKA II stations. We will develop methods to handle the potential issues with real surface station data.

\section{Acknowledgments}

YM and TM thank the members of Data Assimilation Research Team, R-CCS, for useful discussions. YM performed the experiments and analyzed and visualized the results. TM is the principal investigator and directed this study with substantial contributions to the development of the entire manuscript. MK provided NHM-LETKF and helped perform the experiments. HS provided the 5-km simulation results, GSM data, and fundamental ideas. KS provided the POTEKA II specifications and represents Meisei electric for the collaborative research about POTEKA II. This study was supported by CREST, JST projects 'Innovating "Big Data Assimilation" technology for revolutionizing very-short-range severe weather prediction' (grant number: JPMJCR1312) and 'EBD: Extreme Big Data - Convergence of Big Data and HPC for Yottabyte Processing' (grant number: JPMJCR1303). The eight POTEKA II stations in Kobe city elementary schools and R-CCS were implemented as part of the collaborative research between R-CCS and Meisei electric. The locations of all elementary schools were provided by the official website of Crisis Management Office, Kobe city government (http://www.city.kobe.lg.jp/ safety/prevention/evacuation/). The very fine Japanese coast data was provided by Global Administrative Areas (http://www.gadm.org/). This research used computational resources of the K computer and FX10 of the High Performance Computing Infrastructure (HPCI) system provided by R-CCS and Information Technology Center, the University of Tokyo, respectively, through the HPCI System Research Project (project IDs: hp150019, hp160162, hp170178, and hp180062).

\section{References}

Brooks, H. E., and C. A. Doswell III, 2002: Deaths in the 3 May 1999 Oklahoma city tornado from a historical perspective. Wea. Forecasting, 17, 354-361.

Chen, F., and R. Avissar, 1994: Impact of land-surface moisture variability on local shallow convective cumulus and precipitation in large-scale models. J. Appl. Meteor, 33, 1382-1401.

Deardorff, J. W., 1973: The use of subgrid transport equations in a three-dimensional model of atmospheric turbulence. J. Fluids Eng., 95, 429-438.

Ducrocq, V., D. Ricard, J.-P. Lafore, and F. Orain, 2002: Storm-scale numerical rainfall prediction for five precipitating events over France: On the importance of the initial humidity field. Wea. Forecasting, 17, 12361256.

Eltahir, E. A. B., and J. S. Pal, 1996: Relationship between surface conditions and subsequent rainfall in convective storms. J. Geophys. Res., 101, 26237-26245.

Evensen, G., 1994: Sequential data assimilation with a nonlinear quasi-geostrophic model using Monte Carlo methods to forecast error statistics. J. Geophys. Res., 99, 10143-10162.

Fujita, T., D. J. Stensrud, and D. C. Dowell, 2007: Surface data assimilation using an ensemble Kalman filter approach with initial condition and model physics uncertainties. Mon. Wea. Rev., 135, 1846-1868.

Gustafsson, N., T. Janjić, C. Schraff, D. Leuenberger, M. Weissmann, H. Reich, P. Brousseau, T. Montmerle, E. Wattrelot, A. Bučánek, M. Mile, R. Hamdi, M. Lindskog, J. Barkmeijer, M. Dahlbom, B. Macpherson, S. Ballard, G. Inverarity, J. Carley, C. Alexander, D. Dowell, S. Liu, Y. Ikuta, and T. Fujita, 2018: Survey of data assimilation methods for convectivescale numerical weather prediction at operational centres. Quart. J. Roy. Meteor. Soc., 144, 1218-1256.

Ha, S.-Y., and C. Snyder, 2014: Influence of surface observations in mesoscale data assimilation using an ensemble Kalman filter. Mon. Wea. Rev., 142, 14891508.

Hacker, J. P., and C. Snyder, 2005: Ensemble Kalman filter assimilation of fixed screen-height observations in a 
parameterized PBL. Mon. Wea. Rev., 133, 3260-3275.

Hunt, B. R., E. J. Kostelich, and I. Szunyogh, 2007: Efficient data assimilation for spatiotemporal chaos: A local ensemble transform Kalman filter. Physica D, 230, 112-126.

Ikawa, M., and K. Saito, 1991: Description of a non-hydrostatic model developed at the Forecast Research Department of the MRI. Technical Report of the Meteorological Research Institute, 28, 238 pp.

Järvinen, H., E. Andersson, and F. Bouttier, 1999: Variational assimilation of time sequences of surface observations with serially correlated error. Tellus, 51, 469488.

Kain, J. S., and J. M. Fritsch, 1990: A one-dimensional entraining/detraining plume model and its application in convective parameterization. J. Atmos. Sci., 47, 2784-2802.

Kain, J. S., and J. M. Fritsch, 1993: Convective parameterization for mesoscale models: The Kain-Fritsch scheme. The Representation of Cumulus Convection in Numerical Models. Emanuel, K. A., and D. J. Raymond (eds.), Meteor. Monogr., 24, Amer. Meteor. Soc., 165-170.

Kato, T., 2006: Structure of the band-shaped precipitation system inducing the heavy rainfall observed over northern Kyushu, Japan on 29 June 1999. J. Meteor. Soc. Japan, 84, 129-153.

Kunii, M., 2014: Mesoscale data assimilation for a local severe rainfall event with the NHM-LETKF system. Wea. Forecasting, 29, 1093-1105.

Kusabiraki, H., Y. Koyama, T. Kanamori, and H. Seko, 2011: Line-shaped precipitation system observed in the Kinki area and heavy rainfall in the Toga River on 28 July 2008. Tenki, 58, 395-412 (in Japanese).

Maejima, Y., M. Kunii, and T. Miyoshi, 2017: 30-secondupdate 100-m-mesh data assimilation experiments: A sudden local rain case in Kobe on 11 September 2014. SOLA, 13, 174-180.

Meng, Z., and F. Zhang, 2007: Tests of an ensemble Kalman filter for mesoscale and regional-scale data assimilation. Part II: Imperfect model experiments. Mon. Wea. Rev., 135, 1403-1423.

Meng, Z., and F. Zhang, 2008: Tests of an ensemble Kalman filter for mesoscale and regional-scale data assimilation. Part III: Comparison with 3DVAR in a real-data case study. Mon. Wea. Rev., 136, 522-540.

Miyoshi, T., 2011: The Gaussian approach to adaptive covariance inflation and its implementation with the local ensemble transform Kalman filter. Mon. Wea. Rev., 139, 1519-1535.

Miyoshi, T., and K. Aranami, 2006: Applying a four-dimensional local ensemble transform Kalman filter (4DLETKF) to the JMA nonhydrostatic model (NHM). SOLA, 2, 128-131.

Miyoshi, T., M. Kunii, J. Ruiz, G.-Y. Lien, S. Sato, T. Ushio, K. Bessho, H. Seko, H. Tomita, and Y. Ishikawa, 2016a: "Big Data Assimilation" revolutionizing severe weather prediction. Bull. Amer. Meteor. Soc., 97, 1347-1354.

Miyoshi, T., G.-Y. Lien, S. Satoh, T. Ushio, K. Bessho, H. Tomita, S. Nishizawa, R. Yoshida, S. A. Adachi, J. Liao, B. Gerofi, Y. Ishikawa, M. Kunii, J. Ruiz, Y. Maejima, S. Otsuka, M. Otsuka, K. Okamoto, and H. Seko, 2016b: "Big Data Assimilation" toward postpetascale severe weather prediction: An overview and progress. Proceedings of the IEEE, 104, 2155-2179.

Nakanishi, M., and H. Niino, 2006: An improved MellorYamada Level-3 model: Its numerical stability and application to a regional prediction of advection fog. Bound.-Layer Meteor., 119, 397-407.

Nakanishi, M., and H. Niino, 2009: Development of an improved turbulence closure model for the atmospheric boundary layer. J. Meteor. Soc. Japan, 87, 895-912.

Ogura, Y., and M. Yoshizaki, 1988: Numerical study of orographic-convective precipitation over the eastern Arabian Sea and the Ghat Mountains during the summer monsoon. J. Atmos. Sci., 45, 2097-2122.

Pielke, R., Jr., and R. E. Carbone, 2002: Weather impacts, forcasts, and policy: An integrated perspective. Bull. Amer. Meteor. Soc., 83, 393-404.

Saito, K., T. Fujita, Y. Yamada, J. Ishida, Y. Kumagai, K. Aranami, S. Ohmori, R. Nagasawa, S. Kumagai, C. Muroi, T. Kato, H. Eito, and Y. Yamazaki, 2006: The operational JMA nonhydrostatic mesoscale model. Mon. Wea. Rev., 134, 1266-1298.

Saito, K., J. Ishida, K. Aranami, T. Hara, T. Segawa, M. Narita, and Y. Honda, 2007: Nonhydrostatic atmospheric models and operational development at JMA. J. Meteor. Soc. Japan, 85B, 271-304.

Schwartz, C. S., G. S. Romine, M. L. Weisman, R. A. Sobash, K. R. Fossell, K. W. Manning, and S. B. Trier, 2015: A real-time convection-allowing ensemble prediction system initialized by mesoscale ensemble Kalman filter analyses. Wea. Forecasting, 30, 1158-1181.

Seko, H., Y. Shoji, and F. Fujibe, 2007: Evolution and air flow structure of a Kanto thunderstorm on 21 July 1999 (the Nerima Heavy Rainfall Event). J. Meteor. Soc. Japan, 85, 455-477.

Seko, H., T. Miyoshi, Y. Shoji, and K. Saito, 2011: Data assimilation experiments of precipitable water vapor using the LETKF system: Intense rainfall event over Japan 28 July 2008. Tellus A, 63, 402-414.

Simmons, K. M., and D. Sutter, 2005: WSR-88D radar, tornado warnings, and tornado casualties. Wea. Forecasting, 20, 301-310.

Shoji, Y., M. Kunii, and K. Saito, 2009: Assimilation of nationwide and global GPS PWV data for a heavy rain event on 28 July 2008 in Hokuriku and Kinki, Japan. SOLA, 5, 45-48.

Stensrud, D. J., M. Xue, L. J. Wicker, K. E. Kelleher, M. P. Foster, J. T. Schaefer, R. S. Schneider, S. G. Benjamin, S. S. Weygandt, J. T. Ferree, and J. P. Tuell, 
2009: Convective-scale Warn-on-Forecast system. Bull. Amer. Meteor. Soc., 90, 1487-1499.

Stensrud, D. J., L. J. Wicker, M. Xue, D. T. Dawson II, N. Yussouf, D. M. Wheatley, T. E. Thompson, N. A. Snook, T. M. Smith, A. D. Schenkman, C. K. Potvin, E. R. Mansell, T. Lei, K. M. Kuhlman, Y. Jung, T. A. Jones, J. Gao, M. C. Coniglio, H. E. Brooks, and K. A. Brewster, 2013: Progress and challenges with Warnon-Forecast. Atmos. Res., 123, 2-16.

Theis, S. E., A. Hense, and U. Damrath, 2005: Probabilistic precipitation forecasts from a deterministic model: A pragmatic approach. Meteor. Appl., 12, 257-268.

Troen, I., and L. Mahrt, 1986: A simple model of the atmospheric boundary layer; Sensitivity to surface evaporation. Bound.-Layer Meteor, 37, 129-148.

Ushio, T., T. Wu, and S. Yoshida, 2015: Review of recent progress in lightning and thunderstorm detection techniques in Asia. Atmos. Res., 154, 89-102.

Wu, T., Y. Takayanagi, S. Yoshida, T. Funaki, T. Ushio, and Z. Kawasaki, 2013: Spatial relationship between lightning narrow bipolar events and parent thunderstorms as revealed by phased array radar. Geophys. Res. Lett., 40, 618-623.

Yoshikawa, E., T. Ushio, Z. Kawasaki, S. Yoshida, T. Morimoto, F. Mizutani, and M. Wada, 2013: MMSE beam forming on fast-scanning phased array weather radar. IEEE Trans. Geosci. Remote Sens., 51, 3077-3088.

Yussouf, N., and D. J. Stensrud, 2010: Impact of phasedarray radar observations over a short assimilation period: Observing system simulation experiments using an ensemble Kalman filter. Mon. Wea. Rev., 138, 517-538.

Yussouf, N., E. R. Mansell, L. J. Wicker, D. M. Wheatley, and D. J. Stensrud, 2013: The ensemble Kalman filter analyses and forecasts of the 8 May 2003 Oklahoma city tornadic supercell storm using single- and doublemoment microphysics schemes. Mon. Wea. Rev., 141, 3388-3412.

Zhang, F., Z. Meng, and A. Aksoy, 2006: Tests of an ensemble Kalman filter for mesoscale and regional-scale data assimilation. Part I: Perfect model experiments. Mon. Wea. Rev., 134, 722-736. 